\title{
Review Article \\ Modulation of Bacterial Multidrug Resistance Efflux Pumps of the Major Facilitator Superfamily
}

\author{
Sanath Kumar, ${ }^{1}$ Mun Mun Mukherjee, ${ }^{2}$ and Manuel F. Varela ${ }^{2}$ \\ ${ }^{1}$ QC Laboratory, Harvest and Post Harvest Technology Division, Central Institute of Fisheries Education (CIFE), \\ Seven Bungalows, Versova, Andheri (W), Mumbai 400061, India \\ ${ }^{2}$ Biology Department, Eastern New Mexico University, Portales, NM 88130, USA
}

Correspondence should be addressed to Manuel F. Varela; manuel.varela@enmu.edu

Received 28 June 2013; Revised 29 September 2013; Accepted 8 October 2013

Academic Editor: Rodrigo E. Mendes

Copyright (c) 2013 Sanath Kumar et al. This is an open access article distributed under the Creative Commons Attribution License, which permits unrestricted use, distribution, and reproduction in any medium, provided the original work is properly cited.

\begin{abstract}
Bacterial infections pose a serious public health concern, especially when an infectious disease has a multidrug resistant causative agent. Such multidrug resistant bacteria can compromise the clinical utility of major chemotherapeutic antimicrobial agents. Drug and multidrug resistant bacteria harbor several distinct molecular mechanisms for resistance. Bacterial antimicrobial agent efflux pumps represent a major mechanism of clinical resistance. The major facilitator superfamily (MFS) is one of the largest groups of solute transporters to date and includes a significant number of bacterial drug and multidrug efflux pumps. We review recent work on the modulation of multidrug efflux pumps, paying special attention to those transporters belonging primarily to the MFS.
\end{abstract}

\section{Introduction}

Drug and multidrug resistant bacterial pathogens that are causative agents of infectious disease constitute a serious public health concern. Bacterial multidrug efflux pump systems of the major facilitator superfamily (MFS) and resistancenodulation-cell division (RND) superfamily represent common mechanisms for bacterial resistance to antimicrobial agents. As such these bacterial transporters make suitable targets for modulation in order to restore the clinical efficacy of relevant chemotherapeutic antibacterial agents. Here, we briefly review the drug transporter systems of the MFS (and to a lesser extent the RND superfamily) and discuss their modulation via regulation of expression and efflux pump transport inhibition.

\section{Bacteria and Pathogenesis}

Bacteria are unicellular, microscopic living organisms that are rod shaped, ball shaped, or spiral shaped when observed under the microscope. Most bacteria are not harmful; rather, they aid in food preparation and digestion, compete with pathogens, provide vitamins to the body, are useful for basic and applied research purposes, and are important in biotechnology. However, less than one percent of the bacteria of different types are responsible for causing bacterial infections. Bacterial cells are capable of quickly reproducing and releasing chemicals and toxins; pathogenic bacteria can cause damage to cells and tissues in the body and cause clinical disease. Some of the common diseases and infections caused by pathogenic strains of bacteria include food poisoning caused by Escherichia coli and Salmonella [16], gastritis and ulcers caused by Helicobacter pylori [7], the sexually transmitted disease gonorrhea caused by Neisseria gonorrhoeae [8], meningitis caused by N. meningitides [9], skin infections like boils, cellulitis, abscesses, wound infections, toxic shock syndrome, pneumonia, and food poisoning caused by Staphylococcus aureus [10-13], and pneumonia, meningitis, otitis, and strep throat caused by streptococcal bacteria [14-16]. Thus, it is important to investigate bacterial mechanisms that confer pathogenesis in order to reduce the conditions that foster their emergence and movement through populations. 


\section{Bacterial Resistance Mechanisms to Antimicrobial Agents}

Antimicrobial chemotherapy is frequently indicated for infections caused by the bacteria mentioned above and others [17]. Bacterial resistance, however, to antimicrobial agents has emerged in many of these pathogens, often confounding treatment efforts [18]. Bacterial pathogens that are resistant to a single drug are also quite frequently resistant to multiple antimicrobial agents and are considered potentially untreatable "superbugs" [19, 20]. Even though some efforts are underway to overcome this problem by developing new lines of antibiotics with novel mechanisms and newly improved activities, bacteria are nonetheless quickly acquiring resistance determinants and are prevailing as multidrug resistant pathogens [21-25]. In the competition between bacteria and antimicrobial agents, pathogenic bacteria are thought to have an upper hand by transferring drug resistance genetic determinants between distinct bacterial species and acquiring resistant phenotypes against most antimicrobial agents [2629]. The spread of antibiotic resistance in the last decade has been a major challenge when dealing with human health concerns [30]. Releasing antibiotics into the environment is also a major cause in the development and emergence of bacterial antibiotic resistances [31-36]. Inappropriate use and misuse of antimicrobials can foster conditions in which less susceptible bacterial variants survive, become adapted to low drug concentrations, and eventually develop resistance $[37,38]$. Interestingly, a bacterial strain that is selected as a single-drug resistant variant by exposure to a single drug is frequently multidrug resistant to antimicrobials that are structurally distinct from the original selective drug [3942]. General mechanisms which are responsible for bacterial resistances to antimicrobial agents are shown in Figure 1 and include (a) alteration of the sites where the drugs are targeted, (b) enzymes that inactivate the antibiotics, (c) decreased membrane permeability, and (d) active efflux of antimicrobials. Bacterial resistance mechanisms such as these mentioned above provide investigators with good cellular targets for potential modulation. Studies of the modulatory effects on bacterial drug resistance mechanisms, especially those dealing with multidrug resistances, may lead to restoration of the efficacy of antimicrobial agents that have previously been less than efficacious in multidrug resistant pathogens.

\section{Antimicrobial Efflux Pumps of Bacteria}

Active efflux as a mechanism for bacterial resistance to inhibitory substances, such as toxic compounds and antibiotics, is mediated by integral membrane transporters, known simply as drug efflux pumps [43]. There are several main categories of active drug efflux pumps that transport drugs against their concentration gradients across the membrane; see Figure 2. The first category consists of pumps, called primary active transporters, which utilize the energy stored in ATP to catalyze transport of drug across the membrane by ATP hydrolysis [44]. The second category consists of pumps, called secondary active transporters, which are driven by the energy stored in ion gradients that are in turn generated by respiration, to catalyze the transport of drug across the membrane [45-48]. These primary and secondary active drug efflux pumps are largely responsible for conferring antibacterial resistances, and in many cases multiple drug resistances [49-51]. These efflux pumps are located on the cytoplasmic or plasma membranes of bacteria and prevent drug accumulation inside the bacterial cells, thereby conferring resistance [40]. A third category of drug pumps, called the phosphotransferase system (PTS), catalyzes the transport of drug with a concomitant phosphorylation of the drug, usually for cellular entry of the drug substrate $[52,53]$. Bacterial genome sequencing projects facilitate the identification of the putative genes responsible for building antimicrobial resistance [54-56]. The genes responsible for building resistance are collectively called a "resistome" [57].

Based on the modes of energy, amino acid sequence similarities, predicted secondary protein structures, known 3D crystal protein structures, and phylogenetic relationships, bacterial drug efflux transporters are classified into five different major superfamilies and are shown in Figure 2: (i) the major facilitator superfamily (MFS) $[58,71]$; (ii) the ATP-binding cassette (ABC) superfamily [72, 73]; (iii) the small multidrug resistance (SMR) superfamily [74]; (iv) the resistance-nodulation-cell division (RND) superfamily [75, 76]; and (v) the multidrug and toxic compound extrusion superfamily (MATE) of transporters [69].

\section{The Major Facilitator Superfamily}

The major facilitator superfamily (MFS) of transporters comprises uniporters, symporters, and antiporters and has been called the uniporter-symporter-antiporter (USA) family [77]; see Table 1 . The MFS was discovered by Henderson and coworkers [78-80]. These investigators found the seemingly distinct transporters of diverse substrates shared similar deduced amino acid sequences, predicted secondary protein structures within the membrane, and evolutionary relatedness [46, 80-83]. Since their initial discovery, the MFS of transporters has become an important and intensive area of investigation $[50,58-60,71,84,85]$. Since many members of the MFS confer bacterial drug and multidrug resistance, these transporters collectively represent a good system for the study of modulation, both at the level of gene expression and of inhibition of drug transport across the membrane. Both of these avenues hold promise for eventually restoring the clinical efficacy of clinically important antimicrobial agents.

5.1. MFS Multidrug Efflux Pumps. The efflux proteins of the MFS (Table 1) belong to the antiporter group, which may be comprised of either monomeric (e.g., qacA/B, $m d f A$, and emrD-3) or multicomponent systems (e.g., EmrAB-TolC) [86]. The genes encoding these efflux pumps are largely chromosomal, but some others such as qac $A / B$ are plasmid borne [121]. About half of the 39 putative drug efflux pumps in the E. coli genome are of the MFS-type, which is about $10 \%$ of all the proteins encoded in the whole genome of this organism $[122,123]$. With the whole genomes of several 


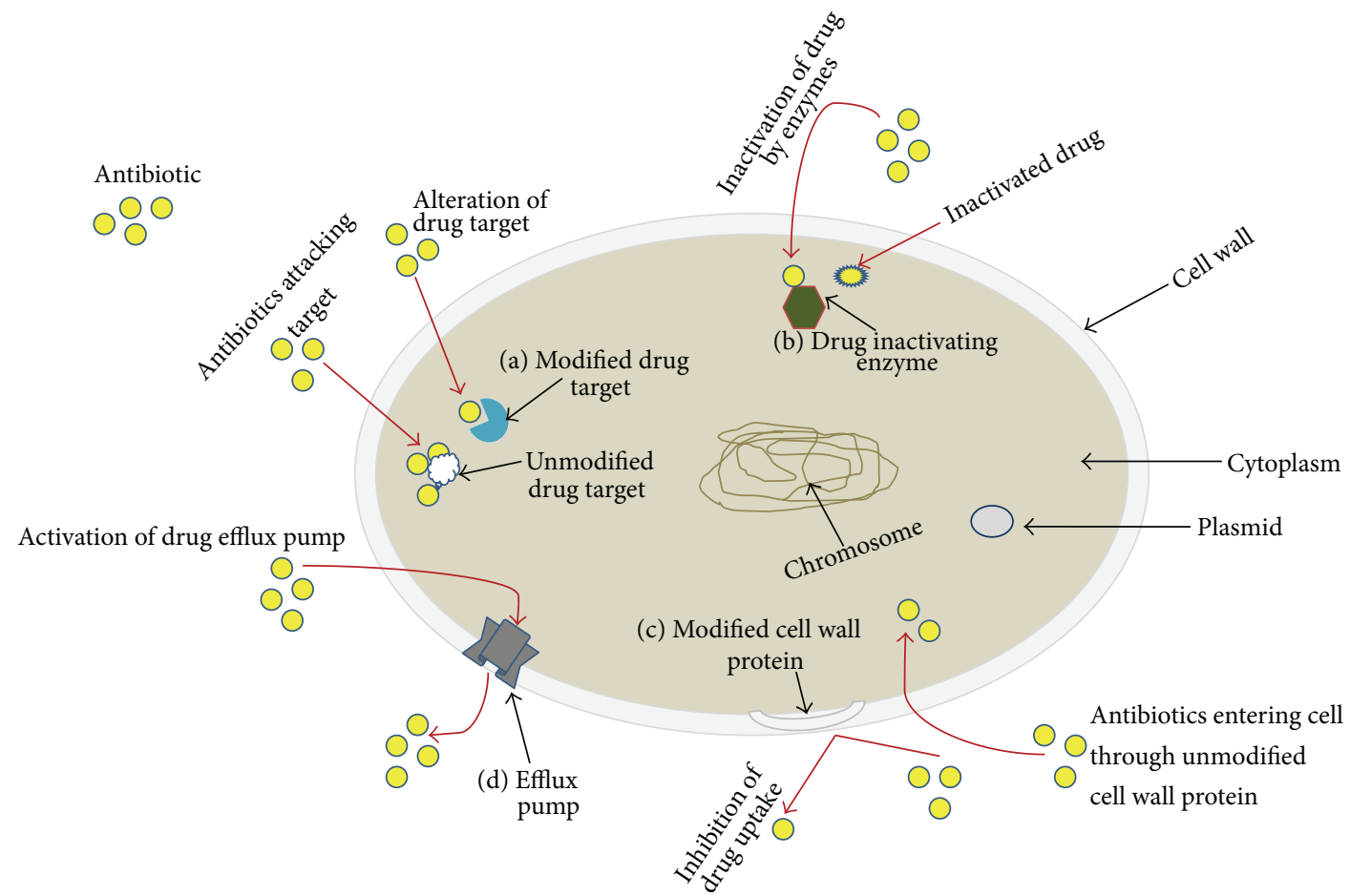

Figure 1: Mechanisms representing antibacterial resistance. A generic bacterium is depicted in which various mechanisms for resistance to antimicrobial agents are indicated. (a) Drug target modification, (b) drug inactivation by enzymes, (c) reduced drug permeability by membrane modification, and (d) active efflux of drugs from the bacterial cell. Yellow circles indicate antimicrobial agent molecules; red arrows indicate movement of molecules, and black arrows are pointing to intra- and extracellular structures.

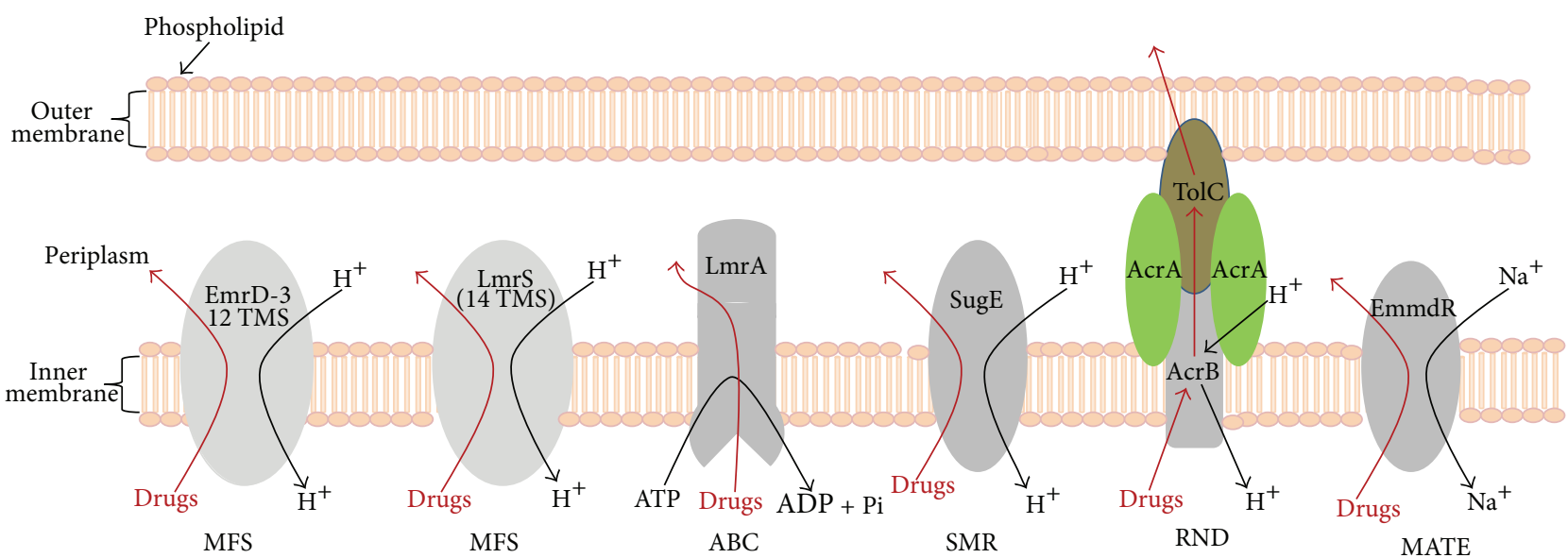

Cytoplasm

Figure 2: Antibacterial resistance by multidrug efflux pumps. Transporters of the MFS are capable of carrying solutes across the biological membrane, and the energy for solute translocation comes from the chemiosmotic gradient of cations [58-60]. EmrD-3 from V. cholerae [61] represents a MFS multidrug efflux pump (a drug/ $\mathrm{H}^{+}$antiporter) with 12 transmembrane domains, and LmrS from S. aureus [62] represents a MFS drug/ $\mathrm{H}^{+}$antiporter with 14 TMS. The transporters of the $\mathrm{ABC}$ superfamily can transport ions, small molecules, and macromolecules in and out of the cell using the hydrolysis of ATP $[63,64]$. The SMR family members confer resistance to quaternary ammonium compounds as well as a variety of antibiotics and are represented by SugE $[65,66]$. The RND superfamily of tripartite efflux pumps works by cation gradients and can be found in both Gram-positive and Gram-negative bacteria [67, 68]. The MATE superfamily of drug efflux pumps extrudes antibiotics out of the bacterial cell via cation gradients and is represented by EmmdR $[69,70]$. Both outer and inner (cytoplasmic) membranes are shown for illustration purposes, as some of the transporters are found in Gram-positive bacteria which lack a second membrane. For clarity, the peptidoglycan is not shown. 
TABLE 1: Efflux pumps of the MFS family with clinically relevant antibiotics as their substrates.

\begin{tabular}{|c|c|c|c|}
\hline Bacterium & Efflux pump & $\begin{array}{l}\text { Antibiotic } \\
\text { substrates }\end{array}$ & References \\
\hline \multirow{3}{*}{ Acinetobacter baumannii } & SmvA & EM & {$[86,87]$} \\
\hline & CraA & $\mathrm{CM}$ & {$[88]$} \\
\hline & $\mathrm{CmlA}$ & $\mathrm{CM}$ & [89] \\
\hline \multirow[t]{3}{*}{ Bacillus subtilis } & Bmr3 & $\mathrm{FQ}, \mathrm{PU}$ & {$[90]$} \\
\hline & $\mathrm{LmrB}$ & $\begin{array}{l}\mathrm{DR}, \mathrm{FQ}, \\
\mathrm{LC}, \mathrm{PU}\end{array}$ & {$[91]$} \\
\hline & MdtP & $\begin{array}{l}\text { AT, FU, } \\
\text { NO, SM }\end{array}$ & {$[92]$} \\
\hline Bordetella bronchiseptica & CmlB1 & $\mathrm{CM}$ & [93] \\
\hline Clostridium difficile & Cme & EM & [94] \\
\hline $\begin{array}{l}\text { Clostridium } \\
\text { saccharolyticum }\end{array}$ & $\operatorname{Tet}(40)$ & TC & [95] \\
\hline Enterobacter aerogenes & QepA & FQ & {$[96]$} \\
\hline Enterococcus faecium & EfmA & FQ & {$[97]$} \\
\hline \multirow[t]{5}{*}{ Escherichia coli } & $\operatorname{Mef}(B)$ & MC & [98] \\
\hline & QepA2 & FQ & [99] \\
\hline & EmrAB-TolC & $\mathrm{FQ}, \mathrm{TE}$ & {$[100]$} \\
\hline & Fsr & $\mathrm{TM}$ & {$[101]$} \\
\hline & MdfA & $\begin{array}{l}\text { FQ, MC, } \\
\text { TE, CM }\end{array}$ & {$[102]$} \\
\hline Enterobacter aerogenes & $\mathrm{CmlB}$ & $\mathrm{CM}$ & {$[103]$} \\
\hline Listeria monocytogenes & Lde & FQ & {$[104]$} \\
\hline Mycobacterium smegmatis & LfrA & FQ & {$[105]$} \\
\hline \multirow[t]{2}{*}{ Salmonella Typhimurium } & EmrAB & $\mathrm{NA}, \mathrm{NO}$ & {$[106]$} \\
\hline & MdfA & $\begin{array}{l}\text { CM, DR, } \\
\text { NF, TC }\end{array}$ & {$[106]$} \\
\hline Serratia marcescens & SmfY & NF & {$[107]$} \\
\hline \multirow[t]{7}{*}{ Staphylococcus aureus } & MdeA & $\begin{array}{l}\text { FU, MU, } \\
\text { NO, VM }\end{array}$ & [108] \\
\hline & NorA & FQ, CM & {$[109]$} \\
\hline & NorB, NorC & FQ & {$[110,111]$} \\
\hline & MsrA & MC & {$[108,112]$} \\
\hline & LmrS & $\begin{array}{l}\text { LZ, EM, } \\
\text { CM, TM, } \\
\text { FU }\end{array}$ & {$[62]$} \\
\hline & SdrM & NF & [113] \\
\hline & $\operatorname{Tet}(38)$ & $\mathrm{TC}$ & {$[111]$} \\
\hline $\begin{array}{l}\text { Stenotrophomonas } \\
\text { maltophilia }\end{array}$ & Smlt0032 & $\mathrm{MC}$ & {$[114]$} \\
\hline Streptococcus agalactiae & $\mathrm{MefB}$ & MC & {$[115]$} \\
\hline Streptococcus pyogenes & MefA & TC & {$[116]$} \\
\hline Streptococcus pneumoniae & MefA, MefE & MC & {$[117,118]$} \\
\hline Streptomyces coelicolor & CmlR1 CmlR2 & CM FP & [119] \\
\hline \multirow[t]{2}{*}{ Vibrio cholerae } & VceCAB & $\begin{array}{l}\text { NA, CM, } \\
\text { EM }\end{array}$ & {$[120]$} \\
\hline & EmrD-3 & LZ, EM & [61] \\
\hline
\end{tabular}

CM: chloramphenicol; DR: doxorubicin; EM: erythromycin; FP: florfenicol FQ: fluoroquinolones; FU: fusidic acid; LC: lincosamides; LZ: linezolid; MC: macrolides; MU: mupirocin; NF: norfloxacin; NO: novobiocin; PU: puromycin; SM: streptomycin; TC: tetracyclines; TM: trimethoprim; VM: virginiamycin. bacteria available now in the public databases, homologues of known efflux pumps can be identified easily by BLAST searches. For example, homologues of EmrD-3, a Vibrio cholerae multidrug efflux pump [61] with $>65 \%$ amino acid identity, could be found in whole genome sequences of a large number of Gram-negative bacteria belonging to Vibrio, Shewanella, aeromonad, enterobacteria, pseudomonad, Moraxella, and Alcaligenes groups. Similarly, a BLAST search using the multidrug efflux pump from a clinical isolate of Staphylococcus aureus (LmrS) [62] identified homologues of this protein in the whole genome sequences of many species of Gram-negative and -positive bacteria, especially in genomes of Staphylococcus and Bacillus. However, it is not known if these homologous proteins have similar substrate profiles, a feature highly unpredictable in the case of drug and multidrug efflux pumps.

5.1.1. Regulation of Efflux Pump Expression. Though, by far, efflux pumps may not confer clinical levels of resistance to antimicrobials, their actions reduce the intracellular concentrations of antibiotics to sublethal levels leading to the development of specific modes of resistance via gene mutations or antibiotic degradation [124, 125]. However, exceptions to this general perception, especially in Grampositive bacteria, have made efflux pumps clinically relevant and are the focus of intense research [124]. Such efflux pumps are either constitutively expressed or expressed at a higher level in clinical isolates or are induced to express at a higher level due to prolonged exposure to antimicrobial compounds [126]. Some of the efflux pump genes are under the tight control of regulators which control their expressions. The genes encoding efflux protein and the regulator of the efflux pump coexist and have overlapping promoters as seen in tetracycline efflux pumps [127]. When there is no antibiotic, the tetracycline repressor prevents the transcription of both efflux and regulatory gene by binding to the operator region. When present in the growth medium, tetracycline binds to the repressor protein preventing it from interacting with the operator thus allowing the transcription of tetA structural genes [127].

The acr and mar Loci Gene Expression. In some instances, global regulatory mechanisms control the expression of efflux pumps, and as a consequence of this, any single mutation in the regulator gene can lead to several efflux pumps being up- or downregulated in a single bacterium $[128,129]$. In E. coli, for example, expression of some of the efflux pumps responsible for bile resistance is regulated by acr and mar loci [130]. Constitutive expression of marA or its orthologs soxS and ramA in some pathogenic bacteria such as Salmonella Typhimurium, Klebsiella pneumoniae, and E. coli could make these microorganisms resistant to organic solvents and multiple drugs $[131,132]$. The role of $m a r A$ and its orthologs has been confirmed by gene deletion experiments in which deletion mutants were found to be more virulent than the wild types [133]. Okusu et al. [134] discovered that the marA-mediated antibiotic resistance was in fact due to the increased expression of the $a c r A B$ efflux pump in $E$. coli. Following this, the roles of marA, acrR, and $\operatorname{ram} A$ in 
antibiotic resistance via the overexpression of efflux pumps have been reported from other Enterobacteriaceae $[135,136]$. In clinical isolates of $E$. coli, a frame shift mutation in marR was responsible for the constitutive overexpression of $\operatorname{mar} A$ and $a c r A B$ resulting in tigecycline resistance [137]. Deletion of AraC-like protein-encoding genes dramatically decreased intestinal colonization in a mouse model [138], while in the case of $S$. Typhimurium DT104, deletion of the gene encoding MarA resulted in the reduced survival in chicken spleen and caecum [139]. These data clearly suggest that multiple virulence genes and genes necessary for survival and colonization are regulated by the $a r a C$ group of proteins. Likewise, deletion of araC orthologues in other pathogenic bacteria such as $P$. aeruginosa (ExsA), V. cholerae (ToxT), and Yersinia pestis $(\mathrm{LcrF})$ also resulted in attenuation of these pathogens in mouse models [140-142]. The araC family of transcriptional regulators such as MarA can regulate, positively or negatively, the expression of several genes including virulence and MDR genes [143]. Due to their critical roles in the survival and virulence of pathogenic bacteria, the $a r a C$ family or similar regulons make ideal targets for the inhibitors.

The fact that overexpression of efflux pumps is induced by the antibiotics during the course of treatment is a serious concern, since such bacteria may show antibiotic sensitivity in laboratory tests. The problem is confounded when efflux pumps are overexpressed by unrelated antibiotics and even antimicrobials like disinfectants and household chemicals $[86,125,144]$. A similar phenomenon has also been observed in gastrointestinal E. coli [145]. The overexpression of TolC has been found to be responsible for clinical Shigella developing fluoroquinolone resistance [146]. The decreased permeability to antibiotics via decreased porin expression has been associated with overexpression of AcrAB [136]. On the other hand, mutations in regulator genes may lead to unregulated expression of the efflux pump conferring constitutive multidrug resistance to the bacterium [147]. Thus, it is important to understand the mechanisms of efflux pump regulation, specifically during antimicrobial treatment. The overexpression of efflux pumps in some clinical strains is responsible for antibiotic resistance, and this mechanism has not been understood well [148]. In a clinical isolate of $K$. pneumoniae, the overexpression of $\mathrm{KmrA}$ and $\mathrm{KdeA}$ confers elevated tolerance to quinolones $[149,150]$.

Bmr and blt Efflux Pumps of B. subtilis and Regulation of Expression. It is intriguing that the bacteria have distinct regulatory mechanisms for homologous efflux pumps, and presumably the chemical and biological inducers of these regulators are also different as seen in the case of two homologous efflux pumps $b m r$ and blt of B. subtilis. bmr is constitutively expressed, while blt is not expressed under normal growth conditions [151]. The expression of $b m r$ is under the control of a regulatory gene $b m r R$, the protein product of which binds to the promoter upstream of $b m r$ gene. The binding of $b m r R$ is stronger in the presence of compounds such as Rhodamine $6 \mathrm{G}$ resulting in higher levels of expression of $b m r$ [152]. A second regulator, BltR, which has no homology with $b m r R$, regulates the expression of $b l t$ [151].
QacA of S. aureus and Regulation of Expression. The role of multiple regulators on the expression of efflux pumps is well elucidated in $S$. aureus and has been recently and extensively reviewed by Schindler et al. [153]. QacA/B efflux pumps are some of the earliest discovered efflux pumps of the MFS family from $S$. aureus that confer resistance to biocides such as quaternary ammonium compounds [121, 154]. This efflux pump has been subjected to intense studies of its transmembrane structure, substrate binding domains, and amino acid residues critical for substrate binding and substrate efflux [50, 155-159]. The expression of qacA is controlled by a repressor protein QacR which is induced by structurally dissimilar compounds [160].

NorA of S. aureus and Regulation of Expression. The other important efflux pump of $S$. aureus, NorA, was initially discovered as a fluoroquinolone-specific pump [161] and later was found to transport several nonquinolone compounds [162]. Several other efflux pumps that are homologous to nor $A$ such as nor $B$ and nor $C$ have been discovered in $S$. aureus, and all these are negatively regulated by MgrA $[110,163]$. The overexpression of nor $A$ in clinical isolates has been observed, and this is due to a mutation in the nor $A$ promoter that resulted in the inability of the regulator protein to bind to the promoter [164]. A two-component regulator ArlSR also has a role in nor A expression, since its deletion from $S$. aureus resulted in constitutive expression of nor A [165]. NorB is negatively regulated by MgrA but positively by NorG [166], though the deletion of norG did not change the fluoroquinolone resistance of $S$. aureus [166]. Though NorG binds to the promoters of nor $A$, nor $B$, nor $C$, and $a b c A$ (a transporter of the $\mathrm{ABC}$-family), its regulatory effect is more pronounced on NorB, since its overexpression resulted in a 3-fold increase in norB transcripts and a 4 -fold increase in quinolone resistance [166]. This study showed that multiple regulators occurring in a single bacterium can have completely different regulatory roles on efflux pumps.

The development of resistance can occur when a bacterium is constantly exposed to an antibacterial agent. $S$. aureus exposed to increasing concentrations of ethidium bromide developed higher levels of resistance to fluoroquinolones and biocides compared to the parent strain, and this increased resistance was due to a several-fold increase in the expression of the nor $A$ efflux gene, which in turn was due to a $70 \mathrm{bp}$ deletion in the nor $A$ promoter region [167].

\section{Modulation of Efflux Pump Activity}

Several studies have demonstrated the development of antibiotic resistance in pathogenic bacteria during the course of antibiotic treatment which involved efflux pumps [20, 25, $40,132,168]$. Therefore, by hypothesis, the antibiotic therapy can be made effective if (i) efflux pumps are inhibited, (ii) the expression of efflux pumps is downregulated, or (iii) the antibiotics are redesigned, so that they are no longer suitable efflux substrates, and thus their clinical efficacy is restored [169].

One of the rational approaches towards confronting efflux of clinically relevant antibiotics is to discover or design potent 
efflux pump inhibitors. In line with the enzyme-substratecompetitive inhibitor concept, it may be hypothesized that if efflux pumps have natural inhibitors, they may also have artificial inhibitors. A number of known compounds have been identified as inhibitors of efflux pumps in addition to novel natural and synthetic products being reported as efflux pump inhibitors [170]. Some efflux pumps are essential for survival, biofilm formation, host colonization, and virulence, and hence their inhibition potentially affects bacterial pathogenesis [124]. To achieve this, critical information on molecular interactions between the efflux pumps and their drug targets, stoichiometry of the drug/proton antiport process, and the regulation of efflux gene expression itself are needed.

\section{Inhibition of RND Bacterial MDR Efflux Pumps}

A brief overview of the scientific literature suggests that new and novel efflux pumps and their preferred antimicrobial substrates are being reported regularly from pathogenic and nonpathogenic bacteria. However, studies to understand the molecular basis of their drug preference, 3-dimensional structures of the efflux pumps, and ways of overcoming them to make antimicrobial therapy more effective are not forthcoming in at the same pace. Despite the lack of physical data on 3-dimensional structures of efflux pumps, bioinformatics tools have helped to understand the efflux pump/drug or efflux pump/proton interactions during active transport to a greater extent. However, this approach also suffers from serious drawbacks when an efflux protein in question does not have close structural homology with proteins whose crystal structures have been determined $[171,172]$. With multidrug resistance efflux pumps, determining the crystal structure for multiple antibiotics is a difficult task. Recent elucidation of crystal structures of some important efflux pumps have helped to understand the structure-function relationships in these pumps. The crystal structure of AcrB with bound minocycline and doxorubicin has been described $[173,174]$. AcrB is a MDR efflux pump with multiple important substrates apart from those used for crystal structure derivation. Using docking tools, the interaction of the AcrB drug-binding pocket with several antibiotics has been studied, and this is an example of how bioinformatics tools can help understanding the efflux pump-drug interactions and the testing of potential efflux pump inhibitors (EPIs) [175]. This in silico study showed different binding pockets for different antimicrobials within the main protein domain [171]. This finding has far reaching implications in the efficacy of competitive EPIs, and due to differences in binding pockets for two different antibiotics of the same efflux pump, a competitive inhibitor may not be able to block the efflux of both antibiotics with the same efficiency $[31,176]$. However, it must also be noted that the docking experiments and in vitro observations on the substrate specificity of efflux pumps may not always correlate as observed in the case of AcrAB-TolC and MexABOprM systems, in which the observed antibiotic specificity did not correlate well with the docking studies [177, 178], and such discrepancies can occur due to unique conformational changes in the efflux proteins upon drug binding which are not contemplated by the docking tools [178]. In Gramnegative bacteria, phenyl-arginine- $\beta$-naphthylamide $(\mathrm{Pa} \beta \mathrm{N})$ has been demonstrated to be a potent EPI and could diminish the norfloxacin resistance activities conferred by Mex efflux systems of Pseudomonas aeruginosa [179], the AcrAB efflux system of the Enterobacteriaceae family [176], and the erythromycin efflux system of Campylobacter jejuni [180].

The ability of a majority of antimicrobial efflux pumps to bind and transport a range of structurally different substrates offers both advantages and disadvantages. From a favorable perspective, there is a greater scope to screen structurally dissimilar compounds as inhibitors of efflux pumps. On the other hand, it is difficult to determine a single structural conformation responsible for drug efflux and to identify specific residues as critical for the transport of a range of substrates [178]. Nevertheless, the possibility remains of using some compounds as efflux pump inhibitors along with the antibiotics, so that the extrusion of the antibiotics does not take place, and thus sufficient intracellular concentration can kill the bacteria. This idea has gathered interest primarily because by doing so successfully, the antibiotics that are otherwise dismissed as ineffective can now be used again clinically [101, 176]. Quinolone derivatives used as competitive inhibitors of the AcrB efflux pump showed varying effects across different Enterobacteriaceae. Also, the effectiveness of an EPI will be different when being used with different antibiotics [181], and this may also depend on the level of expression of efflux pumps as well as the relative affinity of the antibiotic binding site for different antibiotics. Recently, the antimicrobial activity of tetracycline was enhanced by the addition of silver to bacterial cells that had been previously resistant to this antimicrobial agent, although the specific drug efflux pump system responsible was not definitively identified in this study [182].

\section{Inhibition of MFS Bacterial MDR Efflux Pumps}

Bacterial drug and multidrug efflux pumps of the MFS are common amongst clinically important pathogens [50, 51, 59, 60, 71, 183]. Multidrug resistant bacterial pathogens compromise the clinical utility of antimicrobial agents during treatment of their infectious disease [20]. Modulation of bacterial multidrug efflux pumps of the MFS would be, therefore, of tremendous importance in order to eventually restore the clinical utility of antimicrobial agents [170, 184].

8.1. CCCP and MFS MDR Pumps. One of the straightforward approaches to inhibiting efflux pumps is to prevent their energization by protons, such as in the case of $\mathrm{drug} / \mathrm{H}^{+}$ antiporters. Since these efflux pumps are potentiated by protons, compounds which have proton scavenging activities can block the activity of these efflux pumps. A well known example of an inhibitor that uses this blocking of energization (energy uncoupler) as a mechanism is carbonyl cyanide $m$-chlorophenylhydrazone (CCCP), which is a proton-conducting uncoupler of the proton potential that 
dissipates the respiration-generated proton gradient and thus inhibits secondary active transporters [185]. CCCP and other proton conductors are frequently used during the initial physiological characterizations of newly discovered drug and multidrug efflux pumps to ascertain whether the new pumps are primary or secondary active transporters. Several natural compounds such as the plant alkaloid reserpine, kaempferol rhamnoside, and capsaicin inhibit NorA function [186, 187]. The mechanism of inhibition for reserpine and kaempferol rhamnoside involves direct binding and competitive inhibition of the efflux pump during drug/ $\mathrm{H}^{+}$antiport [188], but the mechanism for capsaicin-mediated inhibition is unclear. Several natural products have been shown to be potent EPIs and have been extensively reviewed elsewhere $[86,169$, 189]. Some of the desirable properties of clinically useful EPIs are that they should be nontoxic to humans and nonhuman animals and should not lead to development of crossresistance to other antibiotics [190], and therefore, careful selection and testing of EPIs are very critical.

8.2. Reserpine and MFS MDR Pumps. Reserpine has long been known to be a competitive inhibitor of both primary and secondary active transporter systems [191, 192]. One of the first transporters of the major facilitator superfamily to be analyzed with reserpine was a multidrug transporter from the Gram-positive bacterium Bacillus subtilis, bmr [193], which had previously been shown to transport ethidium bromide and confer resistance to structurally distinct antimicrobial agents, such as rhodamine, chloramphenicol, puromycin, tetraphenylphosphonium, and cetyltrimethylammonium bromide [194]. The reserpine inhibition study showed that in cells with reduced accumulation of ethidium bromide by bmr, the reduced drug accumulation was reversed by reserpine and that ethidium bromide efflux from preloaded cells containing $b m r$ was completely abolished by reserpine [193]. Random mutagenesis of the $b m r$ gene, selection of mutants that lost reserpine sensitivity and DNA sequencing of the $b m r$ genes of the mutants, showed that the residues Phe-143, Val-286, and Phe-306 had been replaced, indicating that reserpine interacts with $\mathrm{bmr}$ at these residues to inhibit drug transport $[195,196]$. Another MFS multidrug efflux pump, NorA from $S$. aureus, is closely related to $b m r$ [194]. Reserpine also effectively inhibited the ethidium bromide transport activities of NorA [162]. Reserpine also affected the transport activities of two distinct MFS-associated chloramphenicol efflux pumps, CmlR1 and CmlR2, from the Gram-positive bacterium Streptomyces coelicolor [119]. The Gram-positive bacterial pathogen Listeria monocytogenes harbors the drug efflux pump, Lde, which confers resistance to the fluoroquinolones ciprofloxacin and norfloxacin and is inhibited by reserpine [104]. In our hands, reserpine reduced the MICs of kanamycin and fusidic acid but not of linezolid and lincomycin in cells harboring the multidrug efflux pump LmrS from a methicillin-resistant $S$. aureus clinical isolate [62] suggesting that reserpine does not completely overlap with the substrate binding sites of multidrug efflux pumps and that inhibition may be dependent on the type and nature of the substrate. Unfortunately, reserpine is neurotoxic and is thus not a suitable agent for chemotherapy against infections caused by bacteria harboring MFS multidrug efflux pumps such as NorA [197].

8.3. Piperine and MFS MDR Pumps. An alkaloid compound, piperine, from pepper plants, was implicated to be an effective inhibitor of ciprofloxacin efflux pump activity in the Grampositive bacterium S. aureus [198]. Piperine is known to inhibit the activities of a variety of bacterial drug transporters [198-201]. MdeA is known to transport ethidium bromide and Hoechst 33342 across the membrane and to confer resistance to the compounds benzalkonium chloride, doxorubicin, daunorubicin, novobiocin, tetraphenylphosphonium chloride, rhodamine $6 \mathrm{G}$, and virginiamycin $[108,202]$. In another study published at about the same time, piperine was found to inhibit drug transport of the multidrug efflux pump, MdeA, from S. aureus [199]. When combined with the antibiotic mupirocin, piperine reduced the MIC of the antibiotic against $S$. aureus by several-fold [199]. Piperine was subsequently found to inhibit ethidium bromide efflux activity from the acid-fast bacterium Mycobacterium smegmatis, although the affected pump was not definitively identified in that study [203]. The mechanism of modulation for piperine, however, is believed to be direct inhibition of drug efflux.

8.4. Inhibitors of NorA Drug Efflux. Two plant-derived alkaloid compounds, called berberine and palmatine, were found to modulate the transporter activity of NorA from $S$. aureus by directly binding to the pump and inhibiting drug transport $[179,204]$. Additionally, a proton pump inhibitor agent used to treat gastroesophageal reflux disease omeprazole and newly synthesized derivative analogues of this compound were found to inhibit norfloxacin transport by the multidrug efflux pump NorA [205]. Interestingly, paroxetine, a serotonin reuptake inhibitor, inhibits drug efflux by NorA as well as other non-MFS drug efflux pumps, such as those of the MATE family $[69,206]$. Derivatives of the quinolone antimicrobial agent ciprofloxacin, called quinolone esters, were found to be poor substrates for NorA and effective inhibitors of drug efflux by NorA [207]. Recently, derivatives of the COX-2 inhibitor celecoxib were found to be potent inhibitors of NorA [208]. Along these lines, derivatives of 2-phenylquinoline were shown to be good inhibitors of ethidium transport by NorA [209].

8.5. Tigecycline and TetA Efflux Pumps. A synthetic derivative of an older antimicrobial agent that successfully restored the efficacy of therapy of bacterial infectious disease treatment was that of tigecycline [210-214]. Originally referred to as a glycylcycline because of a synthetic addition of a glycine moiety to the tetracycline derivative minocycline, tigecycline became an important member of the glycylcycline antimicrobial agents $[215,216]$. As such tigecycline was quite effective in treating bacterial infections caused by both Gram-positive and Gram-negative pathogens [217, 218]. Tigecycline was found to circumvent the activity of the class B tetracycline efflux pump (TetB) thus inhibiting the growth of TetBharboring host bacteria that were resistant to tetracycline [213]. This property of tigecycline is known as a bypass 
mechanism when considered in light of its relationship to bacterial multidrug efflux. Unfortunately, bacterial resistance to tigecycline has emerged, thus confounding the clinical efficacy of this agent [219]. A multidrug efflux pump belonging to the RND family of transporters was found to be largely responsible for resistance to tigecycline [220]. A tetracycline derivative called DMG-DMDOT $(9-(N, N-$ dimethylglycylamido)-6-demethyl-6-deoxytetracycline) is a glycylcycline that was found to be a neither a substrate nor an inhibitor of TetB but rather a good inducer of TetB protein expression by its binding to the TetR repressor protein [221]. Further work will be necessary to enhance the effectiveness of these modulators that bypass multidrug efflux pumps as a mechanism.

8.6. Capsaicin and NorA. In a more recently published study, capsaicin, a plant compound used in foods, was found to inhibit the transport of the fluorescent reagent ethidium bromide across the membrane in $S$. aureus cells containing NorA [186]. In the same study, the authors found that capsaicin also prevented $S$. aureus invasion of macrophage cells in culture [186]. Newer and related plant-derived compounds may also be promising toward efflux pump transport modulation.

\section{Concluding Remarks}

In summary, modulation of bacterial drug and multidrug efflux pumps is an important approach to understanding how bacterial resistances may be circumvented in order to restore the clinical efficacy of chemotherapy against presently recalcitrant infectious diseases. We predict that this restorative goal for currently compromised therapeutics will be accomplished by conducting mechanistic molecular studies of drug and multidrug translocation across the membrane and the modulation of both the expression and transport activities of bacterial multidrug efflux pumps.

\section{Acknowledgment}

This paper was supported by a Grant from the National Institute of General Medical Sciences (P20GM103451) of the National Institutes of Health.

\section{References}

[1] M. F. Bavaro, "E. coli O157:H7 and other toxigenic strains: the curse of global food distribution," Current Gastroenterology Reports, vol. 14, pp. 317-323, 2012.

[2] C. K. Porter, M. S. Riddle, D. R. Tribble et al., "A systematic review of experimental infections with enterotoxigenic Escherichia coli (ETEC)," Vaccine, vol. 29, no. 35, pp. 5869-5885, 2011.

[3] K. Nishikawa, "Recent progress of Shiga toxin neutralizer for treatment of infections by Shiga toxin-producing Escherichia coli," Archivum Immunologiae et Therapiae Experimentalis, vol. 59, no. 4, pp. 239-247, 2011.

[4] P. Garai, D. P. Gnanadhas, and D. Chakravortty, "Salmonella enterica serovars Typhimurium and Typhi as model organisms: revealing paradigm of host-pathogen interactions," Virulence, vol. 3, pp. 377-388, 2012.

[5] S. A. Zaki and S. Karande, "Multidrug-resistant typhoid fever: a review," Journal of Infection in Developing Countries, vol. 5, no. 5, pp. 324-337, 2011.

[6] J.-P. Lavigne and A.-B. Blanc-Potard, "Molecular evolution of Salmonella enterica serovar Typhimurium and pathogenic Escherichia coli: from pathogenesis to therapeutics," Infection, Genetics and Evolution, vol. 8, no. 2, pp. 217-226, 2008.

[7] P. Malfertheiner, M. Selgrad, and J. Bornschein, "Helicobacter pylori: clinical management," Current Opinion in Gastroenterology, vol. 28, pp. 608-614, 2012.

[8] J. W. Tapsall, "Antibiotic resistance in Neisseria gonorrhoeae," Clinical Infectious Diseases, vol. 41, supplement 4, pp. S263S268, 2005.

[9] A. J. Williams and S. Nadel, "Bacterial meningitis: current controversies in approaches to treatment," CNS Drugs, vol. 15, no. 12, pp. 909-919, 2001.

[10] R. R. Watkins, M. Z. David, and R. A. Salata, "Current concepts on the virulence mechanisms of meticillin-resistant Staphylococcus aureus," Journal of Medical Microbiology, vol. 61, pp. 1179-1193, 2012.

[11] S. Y. C. Tong, L. F. Chen, and V. G. Fowler Jr., "Colonization, pathogenicity, host susceptibility, and therapeutics for Staphylococcus aureus: what is the clinical relevance?" Seminars in Immunopathology, vol. 34, no. 2, pp. 185-200, 2012.

[12] M. Y. Lin and M. K. Hayden, "Methicillin-resistant Staphylococcus aureus and vancomycin-resistant Enterococcus: recognition and prevention in intensive care units," Critical Care Medicine, vol. 38, no. 8, pp. S335-S344, 2010.

[13] S. J. Rehm, "Staphylococcus aureus: the new adventures of a legendary pathogen," Cleveland Clinic Journal of Medicine, vol. 75, no. 3, pp. 177-192, 2008.

[14] Å. Örtqvist, J. Hedlund, and M. Kalin, "Streptococcus pneumoniae: epidemiology, risk factors, and clinical features," Seminars in Respiratory and Critical Care Medicine, vol. 26, no. 6, pp. 563574, 2005.

[15] N. N. Lynskey, R. A. Lawrenson, and S. Sriskandan, "New understandings in Streptococcus pyogenes," Current Opinion in Infectious Diseases, vol. 24, no. 3, pp. 196-202, 2011.

[16] T. Q. Tan, "Antibiotic resistant infections due to Streptococcus pneumoniae: impact on therapeutic options and clinical outcome," Current Opinion in Infectious Diseases, vol. 16, no. 3, pp. 271-277, 2003.

[17] C. Walsh, Antibiotics: Actions, Origins, Resistance, ASM Press, Washington, DC, USA, 2003.

[18] S. B. Levy, "Antimicrobial resistance: a global perspective," Advances in Experimental Medicine and Biology, vol. 390, pp. 1-13, 1995.

[19] A. Morris, J. D. Kellner, and D. E. Low, "The superbugs: evolution, dissemination and fitness," Current Opinion in Microbiology, vol. 1, no. 5, pp. 524-529, 1998.

[20] S. B. Levy, "Antibiotic resistance-The problem intensifies," Advanced Drug Delivery Reviews, vol. 57, no. 10, pp. 1446-1450, 2005.

[21] G. D. Wright, "Molecular mechanisms of antibiotic resistance," Chemical Communications, vol. 47, no. 14, pp. 4055-4061, 2011.

[22] D. G. Maki, N. Safdar, and S. C. Ebert, "Prevalence, consequences, and solutions," Pharmacotherapy, vol. 27, no. 10, pp. 121S-125S, 2007. 
[23] A. C. Croft, A. V. D’Antoni, and S. L. Terzulli, "Update on the antibacterial resistance crisis," Medical Science Monitor, vol. 13, no. 6, pp. 103-118, 2007.

[24] A. T. A. El-Tahawy, "The crisis of antibiotic-resistance in bacteria," Saudi Medical Journal, vol. 25, no. 7, pp. 837-842, 2004.

[25] H. C. Neu, “The crisis in antibiotic resistance," Science, vol. 257, no. 5073, pp. 1064-1073, 1992.

[26] S. T. Chancey, D. Zahner, and D. S. Stephens, "Acquired inducible antimicrobial resistance in Gram-positive bacteria," Future Microbiology, vol. 7, pp. 959-978, 2012.

[27] J. M. Rodríguez-Martínez, M. E. Cano, C. Velasco, L. MartínezMartínez, and Á. Pascual, "Plasmid-mediated quinolone resistance: an update," Journal of Infection and Chemotherapy, vol. 17, no. 2, pp. 149-182, 2011.

[28] G. D. Wright, "The antibiotic resistome: the nexus of chemical and genetic diversity," Nature Reviews Microbiology, vol. 5, no. 3, pp. 175-186, 2007.

[29] N. Al Naiemi, B. Duim, P. H. M. Savelkoul et al., "Widespread transfer of resistance genes between bacterial species in an intensive care unit: implications for hospital epidemiology," Journal of Clinical Microbiology, vol. 43, no. 9, pp. 4862-4864, 2005.

[30] G. L. French, "The continuing crisis in antibiotic resistance," International Journal of Antimicrobial Agents, vol. 36, no. 3, pp. S3-S7, 2010.

[31] G. D. Wright, "Antibiotic resistance in the environment: a link to the clinic?" Current Opinion in Microbiology, vol. 13, no. 5, pp. 589-594, 2010.

[32] C. Walsh and S. Fanning, "Antimicrobial resistance in foodborne pathogens-A cause for concern?" Current Drug Targets, vol. 9, no. 9, pp. 808-815, 2008.

[33] V. M. D'Costa, E. Griffiths, and G. D. Wright, "Expanding the soil antibiotic resistome: exploring environmental diversity," Current Opinion in Microbiology, vol. 10, no. 5, pp. 481-489, 2007.

[34] R. I. Aminov and R. I. Mackie, "Evolution and ecology of antibiotic resistance genes," FEMS Microbiology Letters, vol. 271, no. 2, pp. 147-161, 2007.

[35] E. K. Silbergeld, J. Graham, and L. B. Price, "Industrial food animal production, antimicrobial resistance, and human health," Annual Review of Public Health, vol. 29, pp. 151-169, 2008.

[36] B. M. Marshall and S. B. Levy, "Food animals and antimicrobials: impacts on human health," Clinical Microbiology Reviews, vol. 24, no. 4, pp. 718-733, 2011.

[37] S. B. Levy, "Antimicrobial resistance: bacteria on the defence. Resistance stems from misguided efforts to try to sterilise our environment," British Medical Journal, vol. 317, pp. 612-613, 1998.

[38] S. B. Levy, "The challenge of antibiotic resistance," Scientific American, vol. 278, no. 3, pp. 46-53, 1998.

[39] M. N. Alekshun and S. B. Levy, "Molecular mechanisms of antibacterial multidrug resistance," Cell, vol. 128, no. 6, pp. 10371050, 2007.

[40] S. B. Levy, "Active efflux, a common mechanism for biocide and antibiotic resistance," Symposium Series Society for Applied Microbiology, no. 31, pp. 65S-71S, 2002.

[41] S. P. Cohen, W. Yan, and S. B. Levy, "A multidrug resistance regulatory chromosomal locus is widespread among enteric bacteria," Journal of Infectious Diseases, vol. 168, no. 2, pp. 484488, 1993.
[42] M. C. Moken, L. M. McMurry, and S. B. Levy, "Selection of multiple-antibiotic-resistant (mar) mutants of Escherichia coli by using the disinfectant pine oil: roles of the mar and $a c r A B$ loci," Antimicrobial Agents and Chemotherapy, vol. 41, no. 12, pp. 2770-2772, 1997.

[43] S. B. Levy, "Active efflux mechanisms for antimicrobial resistance," Antimicrobial Agents and Chemotherapy, vol. 36, no. 4, pp. 695-703, 1992.

[44] C. F. Higgins, "Multiple molecular mechanisms for multidrug resistance transporters," Nature, vol. 446, no. 7137, pp. 749-757, 2007.

[45] P. J. Henderson, "Studies of translocation catalysis," Bioscience Reports, vol. 11, pp. 453-477, 1991.

[46] P. J. F. Henderson, "The 12-transmembrane helix transporters," Current Opinion in Cell Biology, vol. 5, no. 4, pp. 708-721, 1993.

[47] R. Krämer, "Functional principles of solute transport systems: concepts and perspectives," Biochimica et Biophysica Acta, vol. 1185, no. 1, pp. 1-34, 1994.

[48] B. Poolman and W. N. Konings, "Secondary solute transport in bacteria," Biochimica et Biophysica Acta, vol. 1183, no. 1, pp. 5-39, 1993.

[49] K. Lewis, "Multidrug resistance pumps in bacteria: variations on a theme," Trends in Biochemical Sciences, vol. 19, no. 3, pp. 119-123, 1994.

[50] I. T. Paulsen, M. H. Brown, and R. A. Skurray, "Protondependent multidrug efflux systems," Microbiological Reviews, vol. 60, no. 4, pp. 575-608, 1996.

[51] S. Kumar and M. F. Varela, "Biochemistry of bacterial multidrug efflux pumps," International Journal of Molecular Sciences, vol. 13, no. 4, pp. 4484-4495, 2012.

[52] T. R. Parr Jr. and M. H. Saier Jr., “The bacterial phosphotransferase system as a potential vehicle for the engry of novel antibiotics," Research in Microbiology, vol. 143, no. 5, pp. 443$447,1992$.

[53] S. Kumar, K. P. Smith, J. L. Floyd, and M. F. Varela, "Cloning and molecular analysis of a mannitol operon of phosphoenolpyruvate-dependent phosphotransferase (PTS) type from Vibrio cholerae O395," Archives of Microbiology, vol. 193, no. 3, pp. 201-208, 2011.

[54] S. Biswas, D. Raoult, and J.-M. Rolain, "A bioinformatic approach to understanding antibiotic resistance in intracellular bacteria through whole genome analysis," International Journal of Antimicrobial Agents, vol. 32, no. 3, pp. 207-220, 2008.

[55] H. Harbottle, S. Thakur, S. Zhao, and D. G. White, "Genetics of antimicrobial resistance," Animal Biotechnology, vol. 17, no. 2, pp. 111-124, 2006.

[56] S. Kumar, I. E. Lindquist, A. Sundararajan et al., "Genome sequence of Non-O1 Vibrio cholerae PS15," Genome Announc, vol. 1, no. 1, Article ID e00227-12, 2013.

[57] G. D. Wright, "The antibiotic resistome," Expert Opinion on Drug Discovery, vol. 5, no. 8, pp. 779-788, 2010.

[58] M. D. Marger and M. H. Saier Jr., "A major superfamily of transmembrane facilitators that catalyse uniport, symport and antiport," Trends in Biochemical Sciences, vol. 18, no. 1, pp. 13-20, 1993.

[59] S. S. Pao, I. T. Paulsen, and M. H. Saier Jr., "Major facilitator superfamily," Microbiology and Molecular Biology Reviews, vol. 62, no. 1, pp. 1-34, 1998.

[60] M. H. Saier, Jr, J. T. Beatty et al., "The major facilitator superfamily," Journal of Molecular Microbiology and Biotechnology, vol. 1, pp. 257-279, 1999. 
[61] K. P. Smith, S. Kumar, and M. F. Varela, "Identification, cloning, and functional characterization of EmrD-3, a putative multidrug efflux pump of the major facilitator superfamily from Vibrio cholerae O395," Archives of Microbiology, vol. 191, no. 12, pp. 903-911, 2009.

[62] J. L. Floyd, K. P. Smith, S. H. Kumar, J. T. Floyd, and M. F. Varela, "LmrS is a multidrug efflux pump of the major facilitator superfamily from Staphylococcus aureus," Antimicrobial Agents and Chemotherapy, vol. 54, no. 12, pp. 5406-5412, 2010.

[63] A. L. Davidson and J. Chen, "ATP-binding cassette transporters in bacteria," Annual Review of Biochemistry, vol. 73, pp. 241-268, 2004.

[64] G. J. Poelarends, P. Mazurkiewicz, and W. N. Konings, "Multidrug transporters and antibiotic resistance in Lactococcus lactis," Biochimica et Biophysica Acta, vol. 1555, no. 1-3, pp. 1-7, 2002.

[65] D. C. Bay, K. L. Rommens, and R. J. Turner, "Small multidrug resistance proteins: a multidrug transporter family that continues to grow," Biochimica et Biophysica Acta, vol. 1778, no. 9, pp. 1814-1838, 2008.

[66] G.-X. He, C. Zhang, R. R. Crow et al., "SugE, a new member of the SMR family of transporters, contributes to antimicrobial resistance in Enterobacter cloacae," Antimicrobial Agents and Chemotherapy, vol. 55, no. 8, pp. 3954-3957, 2011.

[67] K. M. Pos, "Drug transport mechanism of the AcrB efflux pump," Biochimica et Biophysica Acta, vol. 1794, no. 5, pp. 782793, 2009.

[68] H. Nikaido and Y. Takatsuka, "Mechanisms of RND multidrug efflux pumps," Biochimica et Biophysica Acta, vol. 1794, no. 5, pp. 769-781, 2009.

[69] T. Kuroda and T. Tsuchiya, "Multidrug efflux transporters in the MATE family," Biochimica et Biophysica Acta, vol. 1794, no. 5, pp. 763-768, 2009.

[70] G.-X. He, C. Thorpe, D. Walsh et al., "EmmdR, a new member of the MATE family of multidrug transporters, extrudes quinolones from Enterobacter cloacae," Archives of Microbiology, vol. 193, no. 10, pp. 759-765, 2011.

[71] M. Saidijam, G. Benedetti, Q. Ren et al., "Microbial drug efflux proteins of the major facilitator superfamily," Current Drug Targets, vol. 7, no. 7, pp. 793-811, 2006.

[72] W. N. Konings and G. J. Poelarends, "Bacterial multidrug resistance mediated by a homologue of the human multidrug transporter P-glycoprotein," IUBMB Life, vol. 53, no. 4-5, pp. 213-218, 2002.

[73] C. Méndez and J. A. Salas, "The role of ABC transporters in antibiotic-producing organisms: drug secretion and resistance mechanisms," Research in Microbiology, vol. 152, no. 3-4, pp. 341-350, 2001.

[74] Y. J. Chung and M. H. Saier Jr., "SMR-type multidrug resistance pumps," Current Opinion in Drug Discovery and Development, vol. 4, no. 2, pp. 237-245, 2001.

[75] C. Daniels and J. L. Ramos, "Adaptive drug resistance mediated by root-nodulation-cell division efflux pumps," Clinical Microbiology and Infection, vol. 15, supplement 1, pp. 32-36, 2009.

[76] K. S. McKeegan, M. I. Borges-Walmsley, and A. R. Walmsley, "The structure and function of drug pumps: an update," Trends in Microbiology, vol. 11, no. 1, pp. 21-29, 2003.

[77] V. C. Goswitz and R. J. Brooker, "Structural features of the uniporter/symporter/antiporter superfamily," Protein Science, vol. 4, no. 3, pp. 534-537, 1995.
[78] M. C. J. Maiden, E. O. Davis, and S. A. Baldwin, "Mammalian and bacterial sugar transport proteins are homologous," Nature, vol. 325, no. 6105, pp. 641-643, 1987.

[79] P. J. F. Henderson, P. E. Roberts, G. E. M. Martin et al., "Homologous sugar-transport proteins in microbes and man," Biochemical Society Transactions, vol. 21, no. 4, pp. 1002-1006, 1993.

[80] J. K. Griffith, M. E. Baker, D. A. Rouch et al., "Membrane transport proteins: implications of sequence comparisons," Current Opinion in Cell Biology, vol. 4, pp. 684-695, 1992.

[81] P. J. F. Henderson, C. K. Hoyle, and A. Ward, "Expression, purification and properties of multidrug efflux proteins," Biochemical Society Transactions, vol. 28, no. 4, pp. 513-517, 2000.

[82] P. J. Henderson and M. C. Maiden, "Homologous sugar transport proteins in Escherichia coli and their relatives in both prokaryotes and eukaryotes," Philosophical transactions of the Royal Society of London B, vol. 326, no. 1236, pp. 391-410, 1990.

[83] M. F. Varela and T. H. Wilson, "Molecular biology of the lactose carrier of Escherichia coli," Biochimica et Biophysica Acta, vol. 1276, no. 1, pp. 21-34, 1996.

[84] P. C. Maloney, "Bacterial transporters," Current Opinion in Cell Biology, vol. 6, no. 4, pp. 571-582, 1994.

[85] M. P. Barrett, A. R. Walmsley, and G. W. Gould, "Structure and function of facilitative sugar transporters," Current Opinion in Cell Biology, vol. 11, no. 4, pp. 496-502, 1999.

[86] X.-Z. Li and H. Nikaido, "Efflux-mediated drug resistance in bacteria," Drugs, vol. 64, no. 2, pp. 159-204, 2004.

[87] H. Nikaido, "Multidrug resistance in bacteria," Annual Review of Biochemistry, vol. 78, pp. 119-146, 2009.

[88] I. Roca, S. Marti, P. Espinal, P. Martínez, I. Gibert, and J. Vila, "CraA, a major facilitator superfamily efflux pump associated with chloramphenicol resistance in Acinetobacter baumannii," Antimicrobial Agents and Chemotherapy, vol. 53, no. 9, pp. 40134014, 2009

[89] J. Vila, S. Martí, and J. Sánchez-Céspedes, "Porins, efflux pumps and multidrug resistance in Acinetobacter baumannii," Journal of Antimicrobial Chemotherapy, vol. 59, no. 6, pp. 1210-1215, 2007.

[90] R. Ohki and M. Murata, "bmr3, a third multidrug transporter gene of Bacillus subtilis," Journal of Bacteriology, vol. 179, no. 4, pp. 1423-1427, 1997.

[91] M. Murata, S. Ohno, M. Kumano, K. Yamane, and R. Ohki, "Multidrug resistant phenotype of Bacillus subtilis spontaneous mutants isolated in the presence of puromycin and lincomycin," Canadian Journal of Microbiology, vol. 49, no. 2, pp. 71-77, 2003.

[92] J.-Y. Kim, T. Inaoka, K. Hirooka et al., "Identification and characterization of a novel multidrug resistance operon, $m d t R P$ (yusOP), of Bacillus subtilis," Journal of Bacteriology, vol. 191, no. 10, pp. 3273-3281, 2009.

[93] K. Kadlec, C. Kehrenberg, and S. Schwarz, "Efflux-mediated resistance to florfenicol and/or chloramphenicol in Bordetella bronchiseptica: identification of a novel chloramphenicol exporter," Journal of Antimicrobial Chemotherapy, vol. 59, no. 2, pp. 191-196, 2007.

[94] S. Lebel, S. Bouttier, and T. Lambert, "The cme gene of Clostridium difficile confers multidrug resistance in Enterococcus faecalis," FEMS Microbiology Letters, vol. 238, no. 1, pp. 93100, 2004.

[95] K. A. Kazimierczak, M. T. Rincon, A. J. Patterson et al., "A new tetracycline efflux gene, tet(40), is located in tandem with 
tet $(\mathrm{O} / 32 / \mathrm{O})$ in a human gut firmicute bacterium and in metagenomic library clones," Antimicrobial Agents and Chemotherapy, vol. 52, no. 11, pp. 4001-4009, 2008.

[96] Y.-J. Park, J. K. Yu, S.-I. Kim, K. Lee, and Y. Arakawa, “Accumulation of plasmid-mediated fluoroquinolone resistance genes, $q e p A$ and $q n r S l$, in Enterobacter aerogenes co-producing RmtB and class A $\beta$-lactamase LAP-1," Annals of Clinical and Laboratory Science, vol. 39, no. 1, pp. 55-59, 2009.

[97] T. Nishioka, W. Ogawa, T. Kuroda, T. Katsu, and T. Tsuchiya, "Gene cloning and characterization of EfmA, a multidrug efflux pump, from Enterococcus faecium," Biological and Pharmaceutical Bulletin, vol. 32, no. 3, pp. 483-488, 2009.

[98] J. Liu, P. Keelan, P. M. Bennett, and V. I. Enne, "Characterization of a novel macrolide efflux gene, mef(B), found linked to sul 3 in porcine Escherichia coli," Journal of Antimicrobial Chemotherapy, vol. 63, no. 3, pp. 423-426, 2009.

[99] V. Cattoir, L. Poirel, and P. Nordmann, "Plasmid-mediated quinolone resistance pump QepA2 in an Escherichia coli isolate from France," Antimicrobial Agents and Chemotherapy, vol. 52, no. 10, pp. 3801-3804, 2008.

[100] O. Lomovskaya and K. Lewis, "Emr, an Escherichia coli locus for multidrug resistance," Proceedings of the National Academy of Sciences of the United States of America, vol. 89, no. 19, pp. 8938-8942, 1992.

[101] F. van Bambeke, J.-M. Pagès, and V. J. Lee, "Inhibitors of bacterial efflux pumps as adjuvants in antibiotic treatments and diagnostic tools for detection of resistance by efflux," Recent Patents on Anti-Infective Drug Discovery, vol. 1, no. 2, pp. 157175, 2006.

[102] R. Edgar and E. Bibi, "MdfA, an Escherichia coli multidrug resistance protein with an extraordinarily broad spectrum of drug recognition," Journal of Bacteriology, vol. 179, no. 7, pp. 2274-2280, 1997.

[103] S. Schwarz, C. Kehrenberg, B. Doublet, and A. Cloeckaert, "Molecular basis of bacterial resistance to chloramphenicol and florfenicol," FEMS Microbiology Reviews, vol. 28, no. 5, pp. 519542, 2004.

[104] S. Godreuil, M. Galimand, G. Gerbaud, C. Jacquet, and P. Courvalin, "Efflux pump lde is associated with fluoroquinolone resistance in Listeria monocytogenes," Antimicrobial Agents and Chemotherapy, vol. 47, no. 2, pp. 704-708, 2003.

[105] X.-Z. Li, L. Zhang, and H. Nikaido, "Efflux pump-mediated intrinsic drug resistance in Mycobacterium smegmatis," Antimicrobial Agents and Chemotherapy, vol. 48, no. 7, pp. 2415-2423, 2004.

[106] K. Nishino, T. Latifi, and E. A. Groisman, "Virulence and drug resistance roles of multidrug efflux systems of Salmonella enterica serovar Typhimurium," Molecular Microbiology, vol. 59, no. 1, pp. 126-141, 2006.

[107] F. Shahcheraghi, Y. Minato, J. Chen et al., "Molecular cloning and characterization of a multidrug efflux pump, SmfY, from Serratia marcescens," Biological and Pharmaceutical Bulletin, vol. 30, no. 4, pp. 798-800, 2007.

[108] J. Huang, P. W. O’Toole, W. Shen et al., "Novel chromosomally encoded multidrug efflux transporter MdeA in Staphylococcus aureus," Antimicrobial Agents and Chemotherapy, vol. 48, no. 3, pp. 909-917, 2004.

[109] K. Ubukata, N. Itoh-Yamashita, and M. Konno, "Cloning and expression of the norA gene for fluoroquinolone resistance in Staphylococcus aureus," Antimicrobial Agents and Chemotherapy, vol. 33, no. 9, pp. 1535-1539, 1989.
[110] Q. C. Truong-Bolduc, J. Strahilevitz, and D. C. Hooper, "NorC: a new efflux pump regulated by MgrA of Staphylococcus aureus," Antimicrobial Agents and Chemotherapy, vol. 50, no. 3, pp. 11041107, 2006.

[111] Q. C. Truong-Bolduc, P. M. Dunman, J. Strahilevitz, S. J. Projan, and D. C. Hooper, "MgrA is a multiple regulator of two new efflux pumps in Staphylococcus aureus," Journal of Bacteriology, vol. 187, no. 7, pp. 2395-2405, 2005.

[112] E. Reynolds, J. I. Ross, and J. H. Cove, "Msr(A) and related macrolide/streptogramin resistance determinants: Incomplete transporters?" International Journal of Antimicrobial Agents, vol. 22, no. 3, pp. 228-236, 2003.

[113] Y. Yamada, K.-I. Hideka, S. Shiota, T. Kuroda, and T. Tsuchiya, "Gene cloning and characterization of SdrM, a chromosomallyencoded multidrug efflux pump, from Staphylococcus aureus," Biological and Pharmaceutical Bulletin, vol. 29, no. 3, pp. 554556, 2006.

[114] L. C. Crossman, V. C. Gould, J. M. Dow et al., "The complete genome, comparative and functional analysis of Stenotrophomonas maltophilia reveals an organism heavily shielded by drug resistance determinants," Genome Biology, vol. 9, no. 4, article R74, 2008.

[115] Y. Cai, F. Kong, and G. L. Gilbert, "Three new macrolide efflux (mef) gene variants in Streptococcus agalactiae," Journal of Clinical Microbiology, vol. 45, no. 8, pp. 2754-2755, 2007.

[116] J. Clancy, J. Petitpas, F. Dib-Hajj et al., "Molecular cloning and functional analysis of a novel macrolide-resistance determinant, mefA, from Streptococcus pyogenes," Molecular Microbiology, vol. 22, no. 5, pp. 867-879, 1996.

[117] G. Pozzi, F. Iannelli, M. R. Oggioni, M. Santagati, and S. Stefani, "Genetic elements carrying macrolide efflux genes in Streptococci," Current Drug Targets, vol. 4, no. 3, pp. 203-206, 2004.

[118] A. Tait-Kamradt, J. Clancy, M. Cronan et al., " $m e f E$ is necessary for the erythromycin-resistant M phenotype in Streptococcus pneumoniae," Antimicrobial Agents and Chemotherapy, vol. 41, no. 10, pp. 2251-2255, 1997.

[119] J. J. Vecchione, B. Alexander Jr., and J. K. Sello, “Two distinct major facilitator superfamily drug efflux pumps mediate chloramphenicol resistance in Streptomyces coelicolor," Antimicrobial Agents and Chemotherapy, vol. 53, no. 11, pp. 4673-4677, 2009.

[120] J. A. Colmer, J. A. Fralick, and A. N. Hamood, "Isolation and characterization of a putative multidrug resistance pump from Vibrio cholerae," Molecular Microbiology, vol. 27, no. 1, pp. 63-72, 1998.

[121] J. M. Tennent, B. R. Lyon, M. Midgley, I. G. Jones, A. S. Purewal, and R. A. Skurray, "Physical and biochemical characterization of the qacA gene encoding antiseptic and disinfectant resistance in Staphylococcus aureus," Journal of General Microbiology, vol. 135, no. 1, pp. 1-10, 1989.

[122] I. T. Paulsen, M. K. Sliwinski, and M. H. Saier Jr., "Microbial genome analyses: global comparisons of transport capabilities based on phylogenies, bioenergetics and substrate specificities," Journal of Molecular Biology, vol. 277, no. 3, pp. 573-592, 1998.

[123] N. Fluman and E. Bibi, "Bacterial multidrug transport through the lens of the major facilitator superfamily," Biochimica et Biophysica Acta, vol. 1794, no. 5, pp. 738-747, 2009.

[124] L. J. V. Piddock, "Clinically relevant chromosomally encoded multidrug resistance efflux pumps in bacteria," Clinical Microbiology Reviews, vol. 19, no. 2, pp. 382-402, 2006. 
[125] K. Poole, "Efflux pumps as antimicrobial resistance mechanisms," Annals of Medicine, vol. 39, no. 3, pp. 162-176, 2007.

[126] L. Fernández, E. B. M. Breidenstein, and R. E. W. Hancock, "Creeping baselines and adaptive resistance to antibiotics," Drug Resistance Updates, vol. 14, no. 1, pp. 1-21, 2011.

[127] W. Hillen and C. Berens, "Mechanisms underlying expression of Tn10 encoded tetracycline resistance," Annual Review of Microbiology, vol. 48, pp. 345-369, 1994.

[128] L. Pumbwe and L. J. V. Piddock, “Two efflux systems expressed simultaneously in multidrug-resistant Pseudomonas aeruginosa," Antimicrobial Agents and Chemotherapy, vol. 44, no. 10, pp. 2861-2864, 2000.

[129] A. M. George, "Multidrug resistance in enteric and other Gramnegative bacteria," FEMS Microbiology Letters, vol. 139, no. 1, pp. 1-10, 1996.

[130] D. G. Thanassi, L. W. Cheng, and H. Nikaido, "Active efflux of bile salts by Escherichia coli," Journal of Bacteriology, vol. 179, no. 8, pp. 2512-2518, 1997.

[131] M. Webber, A. M. Buckley, L. P. Randall, M. J. Woodward, and L. J. V. Piddock, "Overexpression of marA, soxS and acrB in veterinary isolates of Salmonella enterica rarely correlates with cyclohexane tolerance," Journal of Antimicrobial Chemotherapy, vol. 57, no. 4, pp. 673-679, 2006.

[132] M. N. Alekshun and S. B. Levy, "Commensals upon us," Biochemical Pharmacology, vol. 71, no. 7, pp. 893-900, 2006.

[133] M. C. Sulavik, M. Dazer, and P. F. Miller, "The Salmonella typhimurium mar locus: molecular and genetic analyses and assessment of its role in virulence," Journal of Bacteriology, vol. 179, no. 6, pp. 1857-1866, 1997.

[134] H. Okusu, D. Ma, and H. Nikaido, "AcrAB efflux pump plays a major role in the antibiotic resistance phenotype of Escherichia coli multiple-antibiotic-resistance (Mar) mutants," Journal of Bacteriology, vol. 178, no. 1, pp. 306-308, 1996.

[135] T. Schneiders, S. G. B. Amyes, and S. B. Levy, "Role of AcrR and $\operatorname{ram} A$ in fluoroquinolone resistance in clinical Klebsiella pneumoniae isolates from Singapore," Antimicrobial Agents and Chemotherapy, vol. 47, no. 9, pp. 2831-2837, 2003.

[136] R. Chollet, C. Bollet, J. Chevalier, M. Malléa, J.-M. Pagès, and A. Davin-Regli, "mar operon involved in multidrug resistance of Enterobacter aerogenes," Antimicrobial Agents and Chemotherapy, vol. 46, no. 4, pp. 1093-1097, 2002.

[137] D. Keeney, A. Ruzin, F. Mcaleese, E. Murphy, and P. A. Bradford, "MarA-mediated overexpression of the AcrAB efflux pump results in decreased susceptibility to tigecycline in Escherichia coli," Journal of Antimicrobial Chemotherapy, vol. 61, no. 1, pp. 46-53, 2008.

[138] E. Hart, J. Yang, M. Tauschek et al., "RegA, an AraC-like protein, is a global transcriptional regulator that controls virulence gene expression in Citrobacter rodentium," Infection and Immunity, vol. 76, no. 11, pp. 5247-5256, 2008.

[139] L. P. Randall, M. C. Bagnall, K. A. Karatzas, N. C. Coldham, L. J. V. Piddock, and M. J. Woodward, "Fitness and dissemination of disinfectant-selected multiple-antibiotic-resistant (MAR) strains of Salmonella enterica serovar Typhimurium in chickens," Journal of Antimicrobial Chemotherapy, vol. 61, no. 1, pp. 156-162, 2008.

[140] Y. Flashner, E. Mamroud, A. Tidhar et al., "Generation of Yersinia pestis attenuated strains by signature-tagged mutagenesis in search of Novel vaccine candidates," Infection and Immunity, vol. 72, no. 2, pp. 908-915, 2004.
[141] P. J. Kang, A. R. Hauser, G. Apodaca et al., "Identification of Pseudomonas aeruginosa genes required for epithelial cell injury," Molecular Microbiology, vol. 24, no. 6, pp. 1249-1262, 1997.

[142] D. E. Higgins, E. Nazareno, and V. J. DiRita, “The virulence gene activator ToxT from Vibrio cholerae is a member of the AraC family of transcriptional activators," Journal of Bacteriology, vol. 174, no. 21, pp. 6974-6980, 1992.

[143] M. N. Alekshun and S. B. Levy, "Characterization of marR superrepressor mutants," Journal of Bacteriology, vol. 181, no. 10, pp. 3303-3306, 1999.

[144] A. Davin-Regli, J.-M. Bolla, C. E. James et al., "Membrane permeability and regulation of drug "influx and efflux" in enterobacterial pathogens," Current Drug Targets, vol. 9, no. 9, pp. 750-759, 2008.

[145] E. Lautenbach, J. P. Metlay, X. Mao et al., "The prevalence of fluoroquinolone resistance mechanisms in colonizing Escherichia coli isolates recovered from hospitalized patients," Clinical Infectious Diseases, vol. 51, no. 3, pp. 280-285, 2010.

[146] J.-Y. Kim, S.-H. Kim, S.-M. Jeon, M.-S. Park, H.-G. Rhie, and B.-K. Lee, "Resistance to fluoroquinolones by the combination of target site mutations and enhanced expression of genes for efflux pumps in Shigella flexneri and Shigella sonnei strains isolated in Korea," Clinical Microbiology and Infection, vol. 14, no. 8, pp. 760-765, 2008.

[147] H. Wang, J. L. Dzink-Fox, M. Chen, and S. B. Levy, "Genetic characterization of highly fluoroquinolone-resistant clinical Escherichia coli strains from China: role of acrR mutations," Antimicrobial Agents and Chemotherapy, vol. 45, no. 5, pp. 15151521, 2001.

[148] C. E. DeMarco, L. A. Cushing, E. Frempong-Manso, S. M. Seo, T. A. A. Jaravaza, and G. W. Kaatz, "Efflux-related resistance to norfloxacin, dyes, and biocides in bloodstream isolates of Staphylococcus aureus," Antimicrobial Agents and Chemotherapy, vol. 51, no. 9, pp. 3235-3239, 2007.

[149] W. Ogawa, M. Koterasawa, T. Kuroda, and T. Tsuchiya, "KmrA multidrug efflux pump from Klebsiella pneumoniae," Biological and Pharmaceutical Bulletin, vol. 29, no. 3, pp. 550-553, 2006.

[150] Y. Ping, W. Ogawa, T. Kuroda, and T. Tsuchiya, "Gene cloning and characterization of KdeA, a multidrug efflux pump from Klebsiella pneumoniae," Biological and Pharmaceutical Bulletin, vol. 30, no. 10, pp. 1962-1964, 2007.

[151] M. Ahmed, L. Lyass, P. N. Markham, S. S. Taylor, N. VazquezLaslop, and A. A. Neyfakh, "Two highly similar multidrug transporters of Bacillus subtilis whose expression is differentially regulated," Journal of Bacteriology, vol. 177, no. 14, pp. 3904-3910, 1995.

[152] M. Ahmed, C. M. Borsch, S. S. Taylor, N. Vázquez-Laslop, and A. A. Neyfakh, "A protein that activates expression of a multidrug efflux transporter upon binding the transporter substrates," Journal of Biological Chemistry, vol. 269, no. 45, pp. 28506-28513, 1994.

[153] B. D. Schindler, P. Jacinto, and G. W. Kaatz, "Inhibition of drug efflux pumps in Staphylococcus aureus: current status of potentiating existing antibiotics," Future Microbiology, vol. 8, pp. 491-507, 2013.

[154] M. H. Brown and R. A. Skurray, "Staphylococcal multidrug efflux protein QacA," Journal of Molecular Microbiology and Biotechnology, vol. 3, no. 2, pp. 163-170, 2001.

[155] B. A. Mitchell, I. T. Paulsen, M. H. Brown, and R. A. Skurray, "Bioenergetics of the staphylococcal multidrug export protein 
QacA: identification of distinct binding sites for monovalent and divalent cations," Journal of Biological Chemistry, vol. 274, no. 6, pp. 3541-3548, 1999.

[156] Z. Xu, B. A. O’Rourke, R. A. Skurray, and M. H. Brown, "Role of transmembrane segment 10 in efflux mediated by the staphylococcal multidrug transport protein QacA," Journal of Biological Chemistry, vol. 281, no. 2, pp. 792-799, 2006.

[157] K. A. Hassan, M. Galea, J. Wu, B. A. Mitchell, R. A. Skurray, and M. H. Brown, "Functional effects of intramembranous proline substitutions in the staphylococcal multidrug transporter QacA," FEMS Microbiology Letters, vol. 263, no. 1, pp. 76-85, 2006.

[158] K. A. Hassan, R. A. Skurray, and M. H. Brown, "Active export proteins mediating drug resistance in staphylococci," Journal of Molecular Microbiology and Biotechnology, vol. 12, no. 3-4, pp. 180-196, 2007.

[159] K. A. Hassan, T. Souhani, R. A. Skurray, and M. H. Brown, "Analysis of tryptophan residues in the staphylococcal multidrug transporter QacA reveals long-distance functional associations of residues on opposite sides of the membrane," Journal of Bacteriology, vol. 190, no. 7, pp. 2441-2449, 2008.

[160] M. A. Schumacher, M. C. Miller, S. Grkovic, M. H. Brown, R. A. Skurray, and R. G. Brennan, "Structural mechanisms of QacR induction and multidrug recognition," Science, vol. 294, no. 5549, pp. 2158-2163, 2001.

[161] H. Yoshida, M. Bogaki, S. Nakamura, K. Ubukata, and M. Konno, "Nucleotide sequence and characterization of the Staphylococcus aureus norA gene, which confers resistance to quinolones," Journal of Bacteriology, vol. 172, no. 12, pp. 69426949, 1990.

[162] A. A. Neyfakh, C. M. Borsch, and G. W. Kaatz, "Fluoroquinolone resistance protein NorA of Staphylococcus aureus is a multidrug efflux transporter," Antimicrobial Agents and Chemotherapy, vol. 37, no. 1, pp. 128-129, 1993.

[163] T. T. Luong, P. M. Dunman, E. Murphy, S. J. Projan, and C. Y. Lee, "Transcription profiling of the $m g r A$ regulon in Staphylococcus aureus," Journal of Bacteriology, vol. 188, no. 5, pp. 1899-1910, 2006.

[164] E. Y. Ng, M. Trucksis, and D. C. Hooper, "Quinolone resistance mediated by norA: physiologic characterization and relationship to $f l q B$, a quinolone resistance locus on the Staphylococcus aureus chromosome," Antimicrobial Agents and Chemotherapy, vol. 38, no. 6, pp. 1345-1355, 1994.

[165] B. Fournier, R. Aras, and D. C. Hooper, "Expression of the multidrug resistance transporter NorA from Staphylococcus aureus is modified by a two-component regulatory system," Journal of Bacteriology, vol. 182, no. 3, pp. 664-671, 2000.

[166] Q. C. Truong-Bolduc and D. C. Hooper, "The transcriptional regulators NorG and MgrA modulate resistance to both quinolones and $\beta$-lactams in Staphylococcus aureus," Journal of Bacteriology, vol. 189, no. 8, pp. 2996-3005, 2007.

[167] I. Couto, S. S. Costa, M. Viveiros, M. Martins, and L. Amaral, "Efflux-mediated response of Staphylococcus aureus exposed to ethidium bromide," Journal of Antimicrobial Chemotherapy, vol. 62, no. 3, pp. 504-513, 2008.

[168] A. E. Aiello, E. L. Larson, and S. B. Levy, "Consumer antibacterial soaps: effective or just risky?" Clinical Infectious Diseases, vol. 45, supplement 2, pp. S137-S147, 2007.

[169] C. Kourtesi, A. R. Ball, Y. Y. Huang et al., "Microbial efflux systems and inhibitors: approaches to drug discovery and the challenge of clinical implementation," The Open Microbiology Journal, vol. 7, pp. 34-52, 2013.
[170] G. D. Wright and A. D. Sutherland, "New strategies for combating multidrug-resistant bacteria," Trends in Molecular Medicine, vol. 13, no. 6, pp. 260-267, 2007.

[171] Y. Takatsuka, C. Chen, and H. Nikaido, "Mechanism of recognition of compounds of diverse structures by the multidrug efflux pump AcrB of Escherichia coli," Proceedings of the National Academy of Sciences of the United States of America, vol. 107, no. 15, pp. 6559-6565, 2010.

[172] X.-Q. Yao, H. Kenzaki, S. Murakami, and S. Takada, "Drug export and allosteric coupling in a multidrug transporter revealed by molecular simulations," Nature Communications, vol. 1, no. 8, article 117, 2010.

[173] S. Murakami, R. Nakashima, E. Yamashita, T. Matsumoto, and A. Yamaguchi, "Crystal structures of a multidrug transporter reveal a functionally rotating mechanism," Nature, vol. 443, no. 7108, pp. 173-179, 2006.

[174] S. Murakami, R. Nakashima, E. Yamashita, and A. Yamaguchi, "Crystal structure of bacterial multidrug efflux transporter AcrB," Nature, vol. 419, no. 6907, pp. 587-593, 2002.

[175] O. Trott and A. J. Olson, "AutoDock vina: improving the speed and accuracy of docking with a new scoring function, efficient optimization, and multithreading," Journal of Computational Chemistry, vol. 31, no. 2, pp. 455-461, 2010.

[176] J.-M. Pagès and L. Amaral, "Mechanisms of drug efflux and strategies to combat them: challenging the efflux pump of Gram-negative bacteria," Biochimica et Biophysica Acta, vol. 1794, no. 5, pp. 826-833, 2009.

[177] E. B. Tikhonova, V. Dastidar, V. V. Rybenkov, and H. I. Zgurskaya, "Kinetic control of TolC recruitment by multidrug efflux complexes," Proceedings of the National Academy of Sciences of the United States of America, vol. 106, no. 38, pp. 16416-16421, 2009.

[178] H. Nikaido and J.-M. Pagès, "Broad-specificity efflux pumps and their role in multidrug resistance of Gram-negative bacteria," FEMS Microbiology Reviews, vol. 36, no. 2, pp. 340-363, 2012.

[179] O. Lomovskaya and W. Watkins, "Inhibition of efflux pumps as a novel approach to combat drug resistance in bacteria," Journal of Molecular Microbiology and Biotechnology, vol. 3, no. 2, pp. 225-236, 2001.

[180] L. Mamelli, J.-P. Amoros, J.-M. Pagès, and J.-M. Bolla, "A phenylalanine-arginine $\beta$-naphthylamide sensitive multidrug efflux pump involved in intrinsic and acquired resistance of Campylobacter to macrolides," International Journal of Antimicrobial Agents, vol. 22, no. 3, pp. 237-241, 2003.

[181] J. Chevalier, A. Mahamoud, M. Baitiche et al., "Quinazoline derivatives are efficient chemosensitizers of antibiotic activity in Enterobacter aerogenes, Klebsiella pneumoniae and Pseudomonas aeruginosa resistant strains," International Journal of Antimicrobial Agents, vol. 36, no. 2, pp. 164-168, 2010.

[182] J. R. Morones-Ramirez, J. A. Winkler, C. S. Spina, and J. J. Collins, "Silver enhances antibiotic activity against gramnegative bacteria," Science Translational Medicine, vol. 5, no. 190, Article ID 190ral81, 2013.

[183] C. J. Law, P. C. Maloney, and D.-N. Wang, "Ins and outs of major facilitator superfamily antiporters," Annual Review of Microbiology, vol. 62, pp. 289-305, 2008.

[184] K. Lewis, "In search of natural substrates and inhibitors of MDR pumps," Journal of Molecular Microbiology and Biotechnology, vol. 3, no. 2, pp. 247-254, 2001.

[185] M. Bentaboulet and A. Kepes, "Counter transport mediated by the lactose permease of Escherichia coli," Biochimica et Biophysica Acta, vol. 471, no. 1, pp. 125-134, 1977. 
[186] N. P. Kalia, P. Mahajan, R. Mehra et al., "Capsaicin, a novel inhibitor of the NorA efflux pump, reduces the intracellular invasion of Staphylococcus aureus," Journal of Antimicrobial Chemotherapy, vol. 67, pp. 2401-2408, 2012.

[187] J. G. Holler, H. C. Slotved, P. Molgaard, C. E. Olsen, and S. B. Christensen, "Chalcone inhibitors of the NorA efflux pump in Staphylococcus aureus whole cells and enriched everted membrane vesicles," Bioorganic \& Medicinal Chemistry, vol. 20, pp. 4514-4521, 2012.

[188] J. G. Holler, S. B. Christensen, H.-C. Slotved et al., "Novel inhibitory activity of the Staphylococcus aureus NorA efflux pump by a kaempferol rhamnoside isolated from Persea lingue Nees," Journal of Antimicrobial Chemotherapy, vol. 67, no. 5, Article ID dks005, pp. 1138-1144, 2012.

[189] A. K. Bhardwaj and P. Mohanty, "Bacterial efflux pumps involved in multidrug resistance and their inhibitors: rejuvinating the antimicrobial chemotherapy," Recent Patents on AntiInfective Drug Discovery, vol. 7, no. 1, pp. 73-89, 2012.

[190] M. I. Garvey and L. J. V. Piddock, “The efflux pump inhibitor reserpine selects multidrug-resistant Streptococcus pneumoniae strains that overexpress the ABC transporters PatA and PatB," Antimicrobial Agents and Chemotherapy, vol. 52, no. 5, pp. 1677$1685,2008$.

[191] S.-I. Akiyama, M. M. Cornwell, M. Kuwano, I. Pastan, and M. M. Gottesman, "Most drugs that reverse multidrug resistance also inhibit photoaffinity labeling of P-glycoprotein by a vinblastine analog," Molecular Pharmacology, vol. 33, no. 2, pp. 144$147,1988$.

[192] J. P. Henry, D. Botton, C. Sagne et al., "Biochemistry and molecular biology of the vesicular monoamine transporter from chromaffin granules," Journal of Experimental Biology, vol. 196, pp. 251-262, 1994.

[193] A. A. Neyfakh, V. E. Bidnenko, and L. B. C. Lan Bo Chen, "Efflux-mediated multidrug resistance in Bacillus subtilis: similarities and dissimilarities with the mammalian system," Proceedings of the National Academy of Sciences of the United States of America, vol. 88, no. 11, pp. 4781-4785, 1991.

[194] A. A. Neyfakh, "The multidrug efflux transporter of Bacillus subtilis is a structural and functional homolog of the Staphylococcus NorA protein," Antimicrobial Agents and Chemotherapy, vol. 36, no. 2, pp. 484-485, 1992.

[195] K. A. Klyachko, S. Schuldiner, and A. A. Neyfakh, "Mutations affecting substrate specificity of the Bacillus subtilis multidrug transporter Bmr," Journal of Bacteriology, vol. 179, no. 7, pp. 2189-2193, 1997.

[196] M. Ahmed, C. M. Borsch, A. A. Neyfakh, and S. Schuldiner, "Mutants of the Bacillus subtilis multidrug transporter Bmr with altered sensitivity to the antihypertensive alkaloid reserpine," Journal of Biological Chemistry, vol. 268, no. 15, pp. 11086-11089, 1993.

[197] P. N. Markham and A. A. Neyfakh, "Inhibition of the multidrug transporter NorA prevents emergence of norfloxacin resistance in Staphylococcus aureus," Antimicrobial Agents and Chemotherapy, vol. 40, no. 11, pp. 2673-2674, 1996.

[198] I. A. Khan, Z. M. Mirza, A. Kumar, V. Verma, and G. N. Qazi, "Piperine: a phytochemical potentiator of ciprofloxacin against Staphylococcus aureus," Antimicrobial Agents and Chemotherapy, vol. 50, no. 2, pp. 810-812, 2006.

[199] Z. M. Mirza, A. Kumar, N. P. Kalia, A. Zargar, and I. A. Khan, "Piperine as an inhibitor of the MdeA efflux pump of Staphylococcus aureus," Journal of Medical Microbiology, vol. 60, no. 10, pp. 1472-1478, 2011.
[200] S. Sharma, M. Kumar, S. Sharma, A. Nargotra, S. Koul, and I. A. Khan, "Piperine as an inhibitor of Rv1258c, a putative multidrug efflux pump of Mycobacterium tuberculosis," Journal of Antimicrobial Chemotherapy, vol. 65, no. 8, Article ID dkq186, pp. 1694-1701, 2010.

[201] P. L. Sangwan, J. L. Koul, S. Koul et al., "Piperine analogs as potent Staphylococcus aureus NorA efflux pump inhibitors," Bioorganic and Medicinal Chemistry, vol. 16, no. 22, pp. 98479857, 2008.

[202] Y. Yamada, S. Shiota, T. Mizushima, T. Kuroda, and T. Tsuchiya, "Functional gene cloning and characterization of MdeA, a multidrug efflux pump from Staphylococcus aureus," Biological and Pharmaceutical Bulletin, vol. 29, no. 4, pp. 801-804, 2006.

[203] G. Jin, J. Zhang, N. Guo et al., "The plant alkaloid piperine as a potential inhibitor of ethidium bromide efflux in Mycobacterium smegmatis," Journal of Medical Microbiology, vol. 60, no. 2, pp. 223-229, 2011.

[204] P.-C. Hsieh, S. A. Siegel, B. Rogers, D. Davis, and K. Lewis, "Bacteria lacking a multidrug pump: a sensitive tool for drug discovery," Proceedings of the National Academy of Sciences of the United States of America, vol. 95, no. 12, pp. 6602-6606, 1998.

[205] C. Vidaillac, J. Guillon, C. Arpin et al., "Synthesis of omeprazole analogues and evaluation of these as potential inhibitors of the multidrug efflux pump NorA of Staphylococcus aureus," Antimicrobial Agents and Chemotherapy, vol. 51, no. 3, pp. 831838, 2007.

[206] G. W. Kaatz, V. V. Moudgal, S. M. Seo, J. B. Hansen, and J. E. Kristiansen, "Phenylpiperidine selective serotonin reuptake inhibitors interfere with multidrug efflux pump activity in Staphylococcus aureus," International Journal of Antimicrobial Agents, vol. 22, no. 3, pp. 254-261, 2003.

[207] M. Pieroni, M. Dimovska, J. P. Brincat et al., "From 6-aminoquinolone antibacterials to 6-amino-7thiopyranopyridinylquinolone ethyl esters as inhibitors of Staphylococcus aureus multidrug efflux pumps," Journal of Medicinal Chemistry, vol. 53, pp. 4466-4480, 2010.

[208] S. Sabatini, F. Gosetto, S. Serritella et al., "Pyrazolo[4,3-c ][1, 2]benzothiazines 5,5-dioxide: a promising new class of staphylococcus aureus NorA efflux pump inhibitors," Journal of Medicinal Chemistry, vol. 55, no. 7, pp. 3568-3572, 2012.

[209] S. Sabatini, F. Gosetto, N. Iraci et al., "Re-evolution of the 2-Phenylquinolines: ligand-based design, synthesis, and biological evaluation of a potent new class of Staphylococcus aureus NorA efflux pump inhibitors to combat antimicrobial resistance," Journal of Medicinal Chemistry, vol. 56, no. 12, pp. 4975-4989, 2013.

[210] G. G. ZhaneL, J. A. Karlowsky, E. Rubinstein, and D. Hoban, “Tigecycline: a novel glycylcycline antibiotic," Expert Review of Anti-Infective Therapy, vol. 4, no. 1, pp. 9-25, 2006.

[211] T.-L. Doan, H. B. Fung, D. Mehta, and P. F. Riska, “Tigecycline: a glycylcycline antimicrobial agent," Clinical Therapeutics, vol. 28, no. 8, pp. 1079-1106, 2006.

[212] G. A. Noskin, "Tigecycline: a new glycylcycline for treatment of serious infections," Clinical Infectious Diseases, vol. 41, supplement 5, pp. S303-S314, 2005.

[213] I. Chopra, "New developments in tetracycline antibiotics: glycylcyclines and tetracycline efflux pump inhibitors," Drug Resistance Updates, vol. 5, no. 3-4, pp. 119-125, 2002.

[214] M. L. Nelson and S. B. Levy, "The history of the tetracyclines," Annals of the New York Academy of Sciences, vol. 1241, no. 1, pp. 17-32, 2011. 
[215] R. T. Testa, P. J. Petersen, N. V. Jacobus, P.-E. Sum, V. J. Lee, and F. P. Tally, "In vitro and in vivo antibacterial activities of the glycylcyclines, a new class of semisynthetic tetracyclines," Antimicrobial Agents and Chemotherapy, vol. 37, no. 11, pp. 2270-2277, 1993.

[216] T. C. Barden, B. L. Buckwalter, R. T. Testa, P. J. Petersen, and V. J. Lee, "Glycylcyclines'. 3. 9-Aminodoxycyclinecarboxamides," Journal of Medicinal Chemistry, vol. 37, no. 20, pp. 3205-3211, 1994.

[217] R. Patel, M. S. Rouse, K. E. Piper, and J. M. Steckelberg, "In vitro activity of GAR-936 against vancomycin-resistant enterococci, methicillin-resistant Staphylococcus aureus and penicillinresistant Streptococcus pneumoniae," Diagnostic Microbiology and Infectious Disease, vol. 38, no. 3, pp. 177-179, 2000.

[218] P. J. Petersen, N. V. Jacobus, W. J. Weiss, P. E. Sum, and R. T. Testa, "In vitro and in vivo antibacterial activities of a novel glycylcycline, the 9-t-butylglycylamido derivative of minocycline (GAR-936)," Antimicrobial Agents and Chemotherapy, vol. 43, no. 4, pp. 738-744, 1999.

[219] Y. Sun, Y. Cai, X. Liu, N. Bai, B. Liang, and R. Wang, "The emergence of clinical resistance to tigecycline," International Journal of Antimicrobial Agents, vol. 41, pp. 110-116, 2013.

[220] T. Hirata, A. Saito, K. Nishino, N. Tamura, and A. Yamaguchi, "Effects of efflux transporter genes on susceptibility of Escherichia coli to tigecycline (GAR-936)," Antimicrobial Agents and Chemotherapy, vol. 48, no. 6, pp. 2179-2184, 2004.

[221] Y. Someya, A. Yamaguchi, and T. Sawai, "A novel glycylcycline, 9-(N,N-dimethylglycylamido)-6-demethyl-6-deoxytetracycline, is neither transported nor recognized by the transposon Tn10-encoded metal-tetracycline $/ \mathrm{H}^{+}$antiporter," Antimicrobial Agents and Chemotherapy, vol. 39, no. 1, pp. 247249, 1995. 

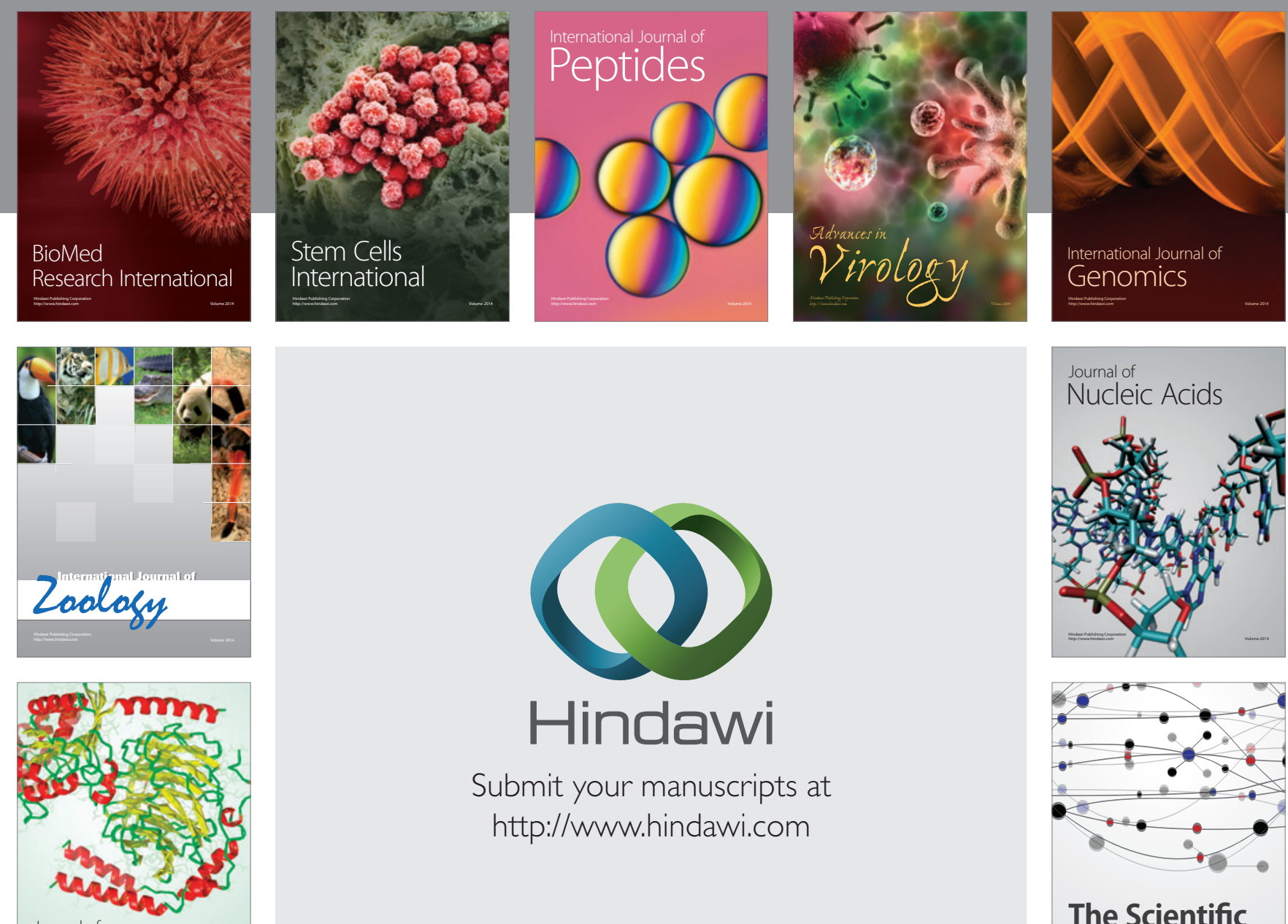

Submit your manuscripts at

http://www.hindawi.com

Journal of
Signal Transduction
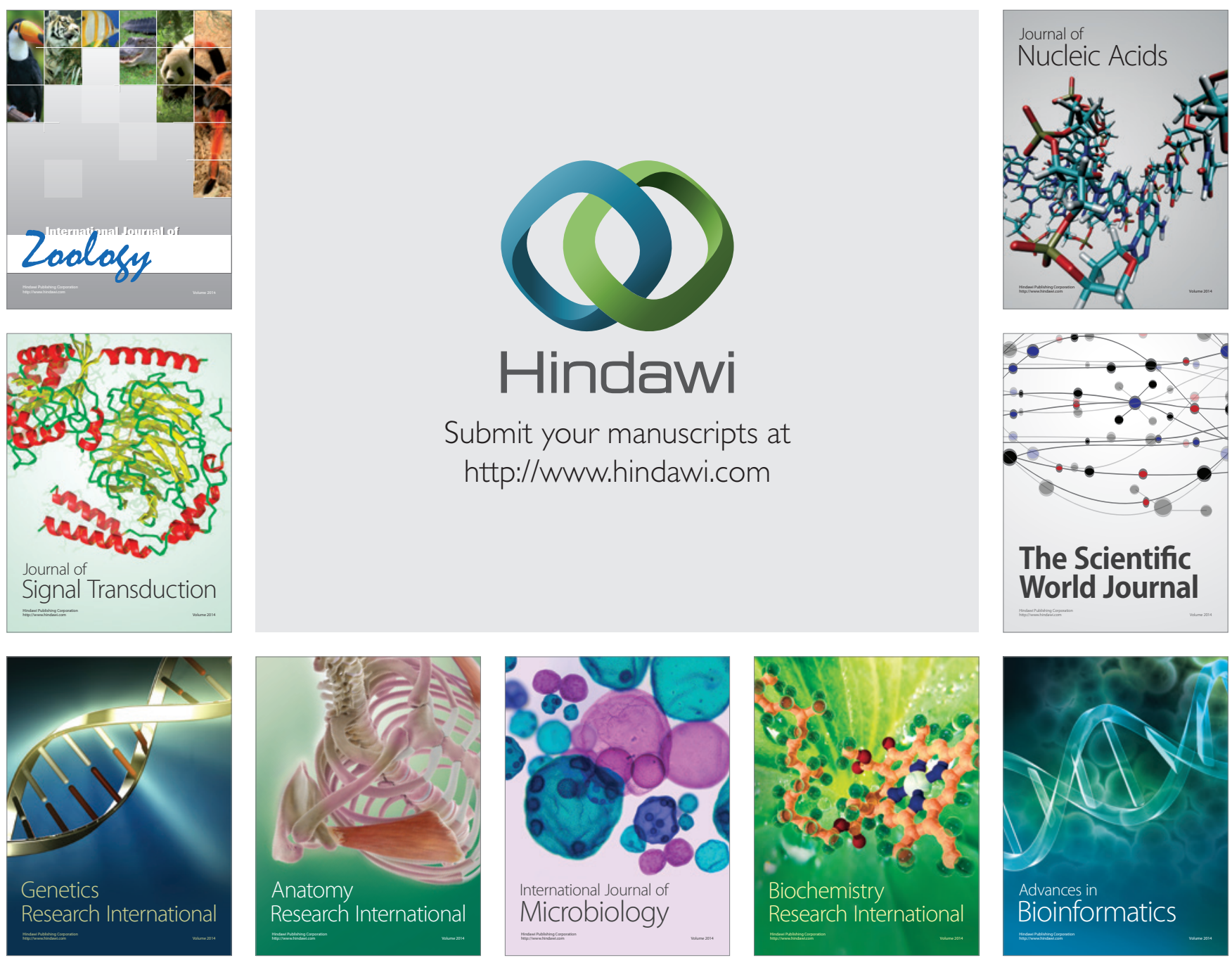

The Scientific World Journal
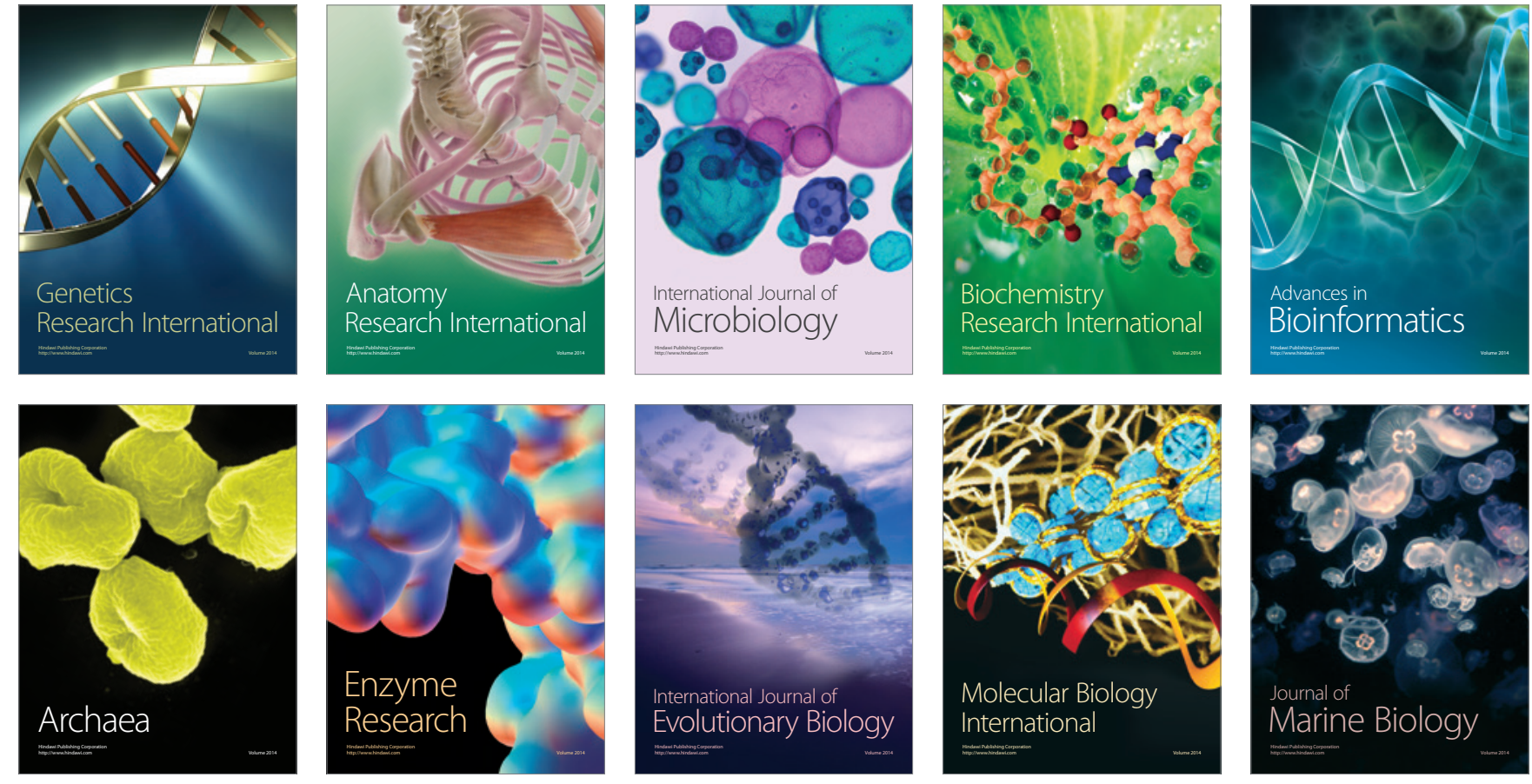